\title{
Trend and Cycle Analysis of Annual and Seasonal Precipitation in Liaoning, China
}

\author{
Taotao Chen, ${ }^{1,2}$ Guimin Xia, ${ }^{1}$ Lloyd T. Wilson, ${ }^{2}$ Wei Chen, ${ }^{3}$ and Daocai Chi ${ }^{1}$ \\ ${ }^{1}$ College of Water Resources, Shenyang Agricultural University, Shenyang 110866, China \\ ${ }^{2}$ Texas A\&M AgriLife Research Center, Texas A\&M University, College Station, TX 77706, USA \\ ${ }^{3}$ Research Institute of Water Resources and Hydropower of Liaoning Province, Shenyang 110003, China \\ Correspondence should be addressed to Daocai Chi; daocaichi@outlook.com
}

Received 22 June 2016; Revised 11 September 2016; Accepted 18 October 2016

Academic Editor: Stefano Dietrich

Copyright (C) 2016 Taotao Chen et al. This is an open access article distributed under the Creative Commons Attribution License, which permits unrestricted use, distribution, and reproduction in any medium, provided the original work is properly cited.

\begin{abstract}
Annual and seasonal precipitation data for 49 meteorological stations over the period of 1960-2006 in Liaoning province were analyzed. Liaoning experienced province-wide decreases in precipitation over the 47-year period, with annual precipitation decreasing by $96 \%$ of the stations, followed by $92,84,63$, and $27 \%$, respectively, for summer, autumn, spring, and winter precipitation. Regional trend analysis confirmed the province-wide decrease, which was detected by the site-specific analysis, but a greater number of significant declines were found for annual, summer, and autumn precipitation for Liaoning province and for three of its four subregions. Four significant cycles with alternation patterns were detected mainly at the time scales of 3-5, 10-11, 20-23, and 31.2 years for each of the four subregions (Liaodong Peninsula, Northeastern Mountain, Western Highland, and Central Plain) and the entire Liaoning province, with the dominant periodicities being 10-11 years. The 10-11-year periodic variation of Liaoning annual precipitation was negatively associated with sunspot activity and positively associated with the East Asian Summer Monsoon (EASM) at the same time scale, while the 31.2-year periodic variation of Liaoning annual precipitation was positively correlated with both the EASM and ENSO activities at the 30-33-year time scale.
\end{abstract}

\section{Introduction}

Global climate has undergone significant and unprecedented changes during the past 100 years $[1,2]$. There is increasing evidence that global warming has resulted in an increase in the frequency and severity of precipitation and drought events [3]. Surface precipitation is an important component of the global climate $[4,5]$ and one of the most important variables in the global hydrological cycle [6] as well as an important indicator in evaluation of water resources. Spatiotemporal trends of precipitation have received increasing attention throughout the world in the past decades [1,7-13]. Some'e et al. [10] analyzed spatiotemporal trends in precipitation and concluded that a noticeable decrease in winter precipitation was observed in northern Iran and the coasts of the Caspian Sea. Zhang et al. [11] studied spatial-temporal precipitation in China over the period of 1956 to 2000 and showed that decreasing precipitation prevailed in the spring and autumn, with winter months receiving increased precipitation. Liang et al. [14] reported that the mean annual and summer precipitation decreased in a southeastern to northwestern trajectory throughout a 48-year period (1961 to 2008) over 98 meteorological stations in Northeast China, of which 77 and 80 climate stations showed decreasing annual and summer trends, respectively.

Liaoning province is located in East Asia's monsoon region and has one of the largest climate change rates in the world [15]. Liaoning is also one of the major grain production regions in China and plays a critical role in maintaining national food security. In the backdrop of changing climate and intensifying human activities, province-wide warming trends have been detected in Liaoning [16, 17], and precipitation is decreased in most of the region $[14,17,18]$. Wide-range decreasing precipitation in Northeast China has resulted in a severe water scarcity problem, which has a negative effect on ecological conservation and agricultural development [14], and a challenge to China's implementation of its "Plan for Increasing the National Grain Production Capacity by 50 Billion Kilograms (2009-2020)." The accelerated hydrological cycle caused by global warming may further exacerbate the 


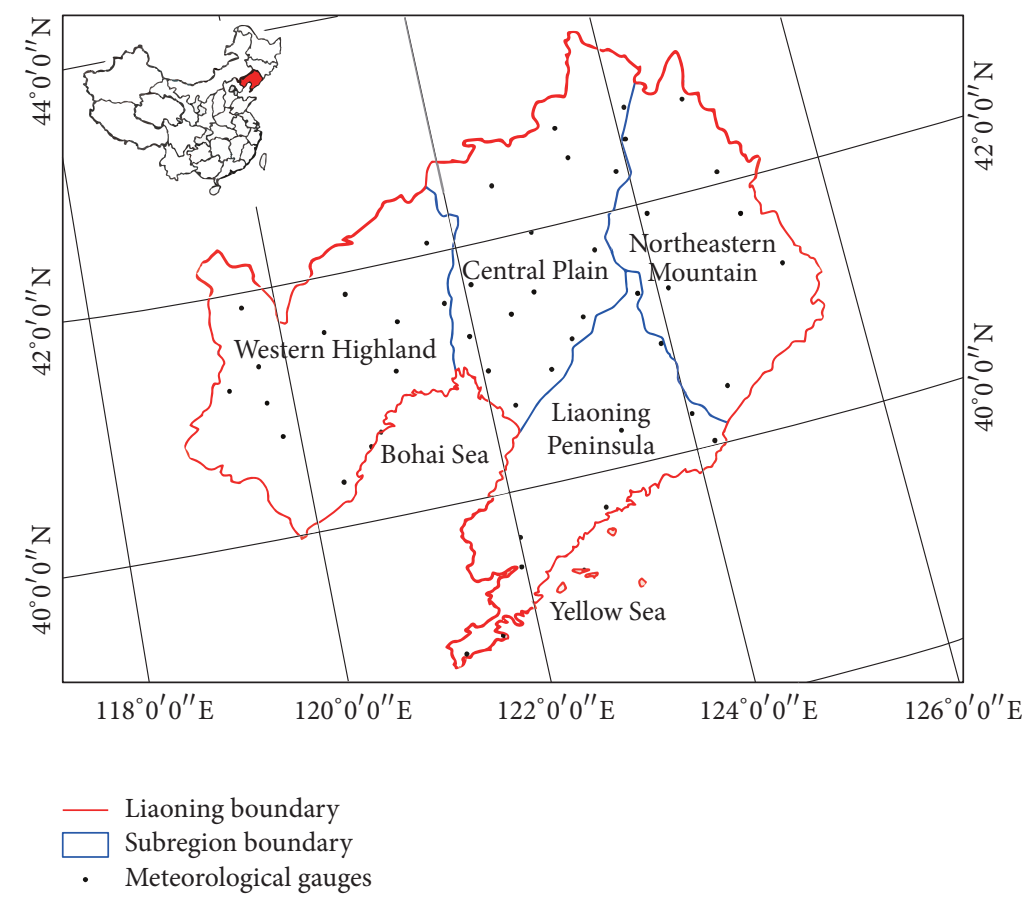

FIGURE 1: Geographical location of Liaoning in China, spatial distribution of four subregions in Liaoning province, and the selected meteorological stations in each subregion. Data were provided by Liaoning Provincial Meteorological Bureau and Hydrographic Bureau.

heterogeneous distribution of precipitation and further limit water resources [19]. A better understanding of precipitation variability and its spatiotemporal changes in Liaoning will lead to development of water management policies that could contribute to increasing grain production and maintaining national food security.

Recently, a number of large precipitation studies have revealed the climatic trend characteristics (trend magnitude, direction, and significance, and abrupt behavior) involving Liaoning province $[8,20-23]$ and precipitation in Northeastern China $[14,16,18,24-26]$. A number of precipitation studies for Liaoning mainly focus on spatiotemporal distribution of precipitation, seasonal precipitation, and extreme precipitation events [27-29]. However, only a limited amount of research has addressed precipitation trends and periodicities characteristics with high-density time series data for Liaoning. Yang et al. [30] detected seasonal and annual precipitation trends in Liaoning, but data only from 8 meteorological stations were used. The objectives of this study are to (1) characterize site-specific precipitation trends (spatial patterns, significant level, magnitudes, and abrupt behavior), (2) detect whether a consistent pattern of regional trend in precipitation exists at a regional scale, and (3) reveal cycle characteristics of regional precipitation at different time scales and its possible causes.

\section{Materials and Methods}

2.1. Study Area. Liaoning province lies between $38^{\circ} 43^{\prime}-$ $43^{\circ} 26^{\prime} \mathrm{N}$ latitude and $118^{\circ} 53^{\prime}-125^{\circ} 46^{\prime} \mathrm{E}$ longitude in China (Figure 1), and has a temperate continental monsoon climate with an average annual precipitation of 500-1000 mm.
The total area of the province is approximately 145,900 square kilometers in size. Liaoning is also known as the "Golden Triangle" from its shape and strategic location for its commercial and cultural advantages and localization on coast and consists essentially of a central lowland, flanked by mountains to the east and west [31]. Based on the topographical and hydrographic characteristics, Liaoning can be divided into four subregions: Northeastern Mountain and Liaodong Peninsula in the east (also collectively referred to as Eastern Mountain), Western Highland, and Central Plain zone (Figure 1). The Northeastern Mountain subregion is dominated by the Changbai Mountain and Qianshan ranges, which extends into the sea to form the Liaodong Peninsula [31]. Precipitation is highest in the Eastern Mountain while it is lowest in the Western Highland, and the Central Plain receives moderate amount of rainfall (Figure 2(a)). The spatial pattern of annual precipitation in Liaoning as a whole decreases from the southeast to the northwest (Figure 3 ). The Northeastern Mountain subregion has the largest precipitation in both annual and seasonal rainfall with a mean annual precipitation of $801 \mathrm{~mm}$. The lowest annual precipitation (442 mm) occurs in the Western Highland subregion. The temporal variabilities of annual and seasonal precipitations over the 47-year period are shown in Figure 2(b). Averaged across the 47 years, the greatest seasonal precipitation is received during the summer, followed by the autumn, spring, and winter, accounting for $65,18,14$, and $3 \%$ of annual precipitation, respectively (Figure 2(b)).

2.2. Data. Daily precipitation data are obtained from Liaoning Provincial Meteorological Bureau and Hydro- 


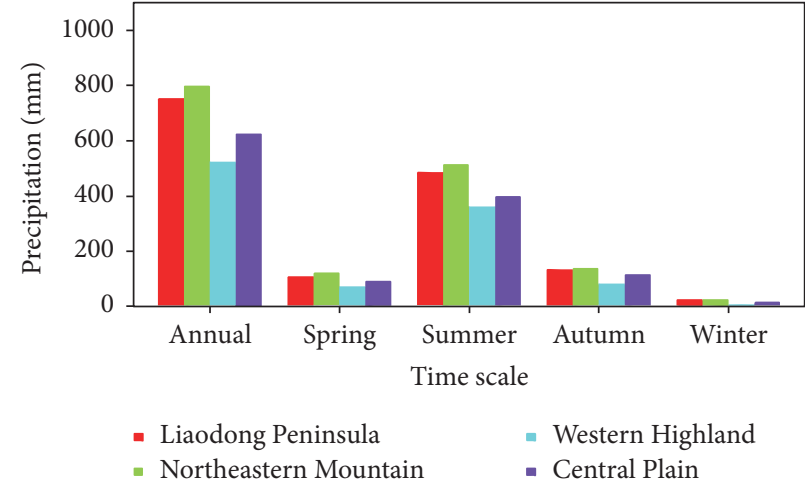

(a)

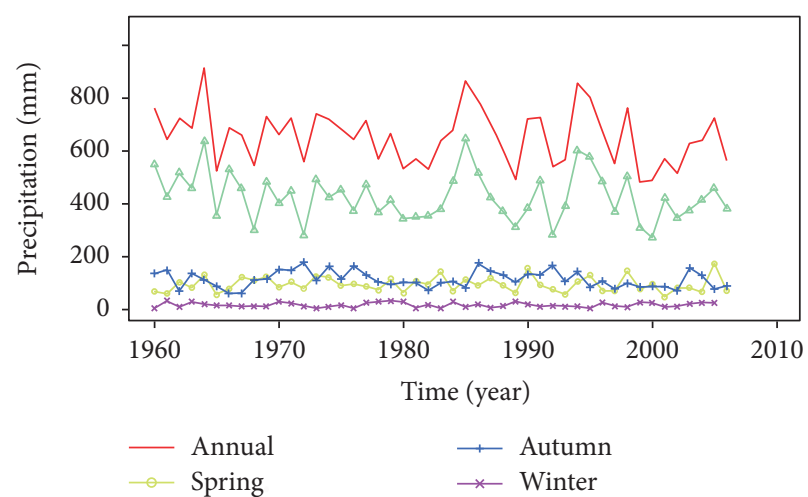

(b)

FIGURE 2: Annual and seasonal precipitation series in Liaoning (a) and mean precipitation for 1960-2006 in different subregions (b).

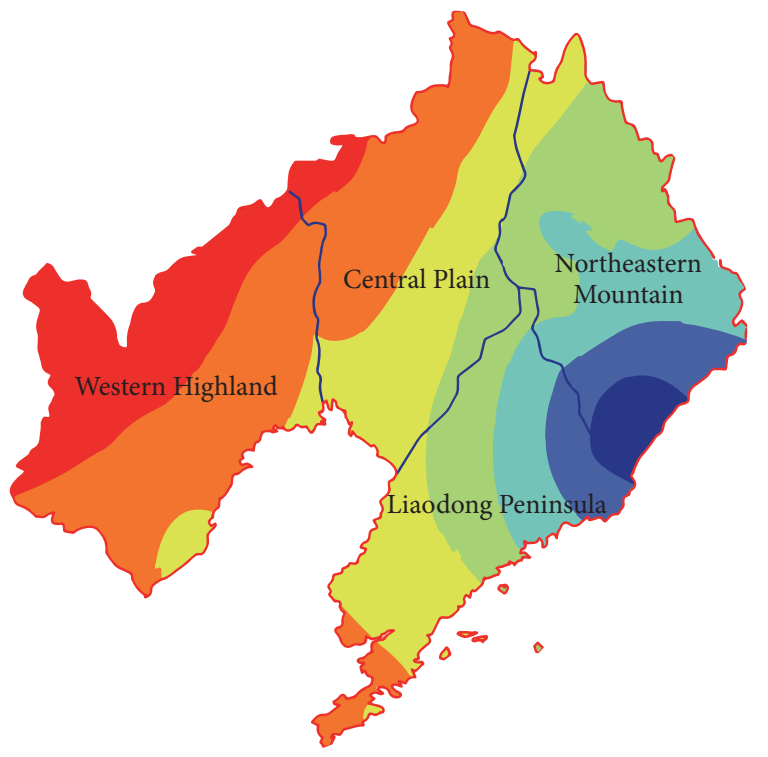

Precipitation (mm)

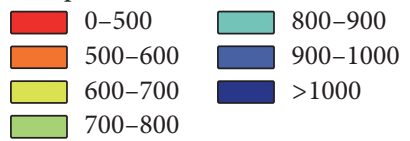

FIGURE 3: Spatial distribution of annual precipitation within the period 1960-2006 in Liaoning province, China.

graphic Bureau for 94 meteorological stations over 19472006. However, only 82 stations in the study area have continuous records over the period from 1960 to 2006, with 49 stations that pass the homogeneity test at a significance level of 0.05 [32] selected for analysis (Figure 1). Missing data are estimated using linear interpolation from neighboring stations when fewer than three consecutive days of precipitation data were missing. The dataset used in the study also included the sunspot number (available at http://www.sidc.be/silso/datafiles), the East Asian Summer
Monsoon (EASM) (http://research.jisao.washington.edu/data sets/globalsstenso/), and the Global-SST ENSO index (http:// ljp.gcess.cn/dct/page/1).

\subsection{Methods}

2.3.1. Mann-Kendall Test and Regional Kendall Test. The Mann-Kendall (MK) nonparametric test is frequently used to quantify the significance of time series trends [33-36]. Its statistic $S$ is calculated as

$$
\begin{array}{r}
S=\sum_{i=1}^{n-1} \sum_{j=i+1}^{n} \operatorname{sgn}\left(x_{j}-x_{i}\right), \\
\operatorname{sgn}\left(x_{j}-x_{i}\right)= \begin{cases}+1, & x_{j}-x_{i}>0, \\
0, & x_{j}-x_{i}=0, \\
-1, & x_{j}-x_{i}<0,\end{cases}
\end{array}
$$

where $n$ is the length of the time series $\left(x_{1}, x_{2}, \ldots x_{n}\right)$ and $x_{i}$ and $x_{j}$ are the $i$ th and $j$ th data point in the time series $(j>i)$, respectively. The variance $V(S)$ of statistic $S$ is obtained as

$$
V(S)=\frac{n(n-1)(2 n+5)-\sum_{k=1}^{m}\left(t_{k}-1\right)\left(2 t_{k}+5\right)}{18},
$$

where $m$ is the number of tied groups and $t_{k}$ denotes the number of ties for the $k$ th value. A tied group is a set of sample data having the same value [12]. The standardized normal test statistical $Z_{s}$ is calculated as

$$
Z_{s}= \begin{cases}\frac{S-1}{\sqrt{V(S)}}, & S>0, \\ 0, & S=0, \\ \frac{S+1}{\sqrt{V(S)}}, & S<0 .\end{cases}
$$

$Z_{s}$ is the standard normal test statistic in cases where the sample size $n>10$. A positive or negative value of $Z_{s}$ indicates an upward or downward trend, respectively. In our analysis, 
MK test is used to detect if a trend in annual and seasonal precipitation series is statistically significant. The significance level of $p=0.05$ is applied.

Helsel and Frans [35] extended the Mann-Kendall test to take into account multiple stations and multiple observations for each station and referred to this as a Regional Kendall Test. The Regional Kendall Test is a nonparametric test to identify the occurrence of consistent pattern of time series trends across a region. The Regional Kendall Test can be generalized to correlated data using a consistent estimator for the covariance described by Dietz and Killeen [37].

2.3.2. Theil-Sen Approach. Theil-Sen's estimator is used to quantify the magnitude of trends and has been widely used in analyzing hydrological time series data $[10,38]$. Theil-Sen's estimator can be calculated as

$$
\begin{aligned}
Q_{\text {med }} & =\operatorname{median}(Q), \\
Q & =\frac{x_{j}-x_{i}}{j-i}, \quad i<j,
\end{aligned}
$$

where $x_{i}$ and $x_{j}$ are the $i$ th and $j$ th data point in the time series $(j>i)$, respectively. Theil-Sen's estimator's main advantage lies in the global median used, which makes it more resistant to the effect of extreme values in the time series $[38,39]$.

2.3.3. Morlet Wavelet Analysis. Wavelet transform analysis is a powerful tool for identifying the main periodicity in nonstationary signals [40] and detect variation at different time scales $[14,41]$. The wavelet transform for a time series $x_{n}(n=0, \ldots, N-1)$ is defined as the convolution of $x_{n}$ with a scaled and translated wavelet $\psi(\eta)$ :

$$
W_{n}(\xi)=\sum_{\gamma=0}^{N-1} x_{\gamma} \psi^{*}\left[\frac{(\gamma-n) \delta t}{\xi}\right] .
$$

The Morlet Wavelet function [41] is defined as

$$
\psi(\eta)=\pi^{-1 / 4} e^{i \omega_{0} \eta} e^{-\eta^{2} / 2},
$$

where $\xi$ is the time scale, $\omega_{0}$ is the nondimensional frequency taken to be 6 for it satisfying the admissibility condition [42], $\eta$ is the time, $\delta t$ is the time interval, and $\psi^{*}[(\gamma-n) \delta t / \xi]$ indicates the complex conjugate of the wavelet function $\psi[(\gamma-n) \delta t / \xi]$. The real part of $W_{n}(\xi)$ and the modulus square of the Morlet Wavelet (wavelet spectral power), $P_{n}(\xi)$, are extensively used to identify the main vibration periodicities. The real part of the Morlet Wavelet shows signal intensity and phase of different characteristics in different time scales, whereas wavelet spectral power exhibits the strength of the signal on the characteristic time scales [26]. Wavelet spectral power at different scale $(\xi)$ can be calculated by

$$
P_{n}(\xi)=\left|W_{n}(\xi)\right|^{2}
$$

Wavelet variance can be calculated by the sum of the square of wavelet coefficients in time domain:

$$
\operatorname{var}(\xi)=\sum_{n=0}^{N-1}\left|W_{n}(\xi)\right|^{2}
$$

2.3.4. Sequential Mann-Kendall Rank Statistic Test. The Sequential Mann-Kendall Rank Statistic (SMKRS) test is used to identify abrupt changes in significant trends [43-46]. This test sets up a progressive series $u(t)$ and a backward series $u^{\prime}(t)$. If the two series cross each other and then diverge and exceed specific threshold values, then there is a statistically significant trend [47]. The threshold values in this study are \pm 1.96 ( $p=0.05$ ), with the crossing point estimating the year at which the trend begins. SMKRS test has the following four steps:

(1) At each comparison, the number of cases $x_{i}>x_{j}$ is counted and indicated by $n_{i}$, where $x_{i}(i=1,2, \ldots, n)$ and $x_{j}(j=1,2, \ldots, i-1)$ are the sequential values in a series, respectively.

(2) The test statistic $t_{i}$ is calculated by

$$
t_{i}=\sum_{j=1}^{i} n_{j}
$$

(3) The mean $E(t)$ and variance $\operatorname{var}\left(t_{i}\right)$ of the test statistic are calculated by

$$
\begin{aligned}
E(t) & =\frac{n(n-1)}{4}, \\
\operatorname{var}\left(t_{i}\right) & =\frac{i(i-1)(2 i+5)}{72} .
\end{aligned}
$$

(4) Sequential progressive value can be calculated as

$$
u(t)=\frac{t_{i}-E(t)}{\sqrt{\operatorname{var}\left(t_{i}\right)}} .
$$

Similarly, sequential backward $\left(u^{\prime}(t)\right)$ analysis of the SMKRS test is calculated starting from the end of the series data according to the procedures (1)-(4).

2.3.5. Calculation and Spatial Interpolation. Four seasons are defined by the standard meteorological definition: spring (March to May), summer (June to August), autumn (September to November), and winter (December to February). The annual and seasonal accumulative precipitation is estimated by summing the daily precipitation data for each of the 49 selected meteorological stations. A prewhitening technique [12] using the sampling lag-1 serial correlation coefficient is applied to the time series before conducting the trend test to eliminate the effect of the autocorrelation of the precipitation time series on the trend estimate. $\mathrm{R}$ software is used to implement the algorithms for the five nonparametric methods (MK trend test, Theil-Sen approach, SMKRS test, Regional Kendall Test, and Morlet Wavelet analysis). Among these nonparametric methods, MK trend test and Regional Kendall Test are implemented by the rkt package in $\mathrm{R}$ [48] while Morlet Wavelet analysis is conducted by biwavelet package developed by Gouhier [49]. Theil-Sen approach is used to quantify the magnitude of precipitation trend for each of 49 selected meteorological stations $\left(\mathrm{mm}_{\mathrm{mear}}{ }^{-1}\right)$. The 
TABLE 1: Number of meteorological stations with significant trends detected by the Mann-Kendall test for the annual and seasonal precipitation series over the period 1960-2006 in Liaoning, China.

\begin{tabular}{|c|c|c|c|c|c|c|}
\hline Precipitation Trend & Significance & Annual & Spring & Summer & Autumn & Winter \\
\hline \multirow{3}{*}{ Negative trend } & Not significant & 44 & 31 & 42 & 38 & 13 \\
\hline & Significant & 3 & 0 & 3 & 3 & 0 \\
\hline & $\%$ & 96 & 63 & 92 & 84 & 27 \\
\hline \multirow{3}{*}{ Positive trend } & Not significant & 2 & 18 & 4 & 8 & 35 \\
\hline & Significant & 0 & 0 & 0 & 0 & 1 \\
\hline & $\%$ & 4 & 37 & 8 & 16 & 73 \\
\hline
\end{tabular}

surface interpolation technique (inverse distance weighted algorithm, IDW) is used to produce a spatial map of precipitation and precipitation trends using ArcGIS 10.2.

\section{Results and Discussion}

3.1. Changes in Annual Precipitation. Figure 4 shows the spatial patterns for both annual and seasonal precipitation trend magnitudes and trend significances of each of the 49 selected meteorological stations in Liaoning province. The results demonstrate that $96 \%$ (46) of the meteorological stations have negative trends in annual precipitation (Table 1), among which three stations (Changtu, Xifeng, and Xiuyan) exhibit a statistically significant negative trend, which occurs in Liaodong Peninsula and the southern part of Northeastern Mountain (Figure 4(a)). Four percent of meteorological stations show nonsignificant positive trends (in Western Highland and Central Plain).

Negative trends in annual precipitation are observed for the entire study area (Figure 4(a)). Liaodong Peninsula and Northeastern Mountain have a greater number of significant negative trends and higher cumulative annual rainfall than Western Highland and Central Plain (Figure 3). The slope of the trend magnitudes gradually declines from the southeast to the northwest direction and varied from $-4.98 \mathrm{~mm}$ year ${ }^{-1}$ to $0.04 \mathrm{~mm}_{\text {year }}{ }^{-1}$. The most negative trend is measured at Fengcheng station in Liaodong Peninsula $\left(-4.98 \mathrm{~mm}\right.$ year $\left.^{-1}\right)$, followed by Xiuyan $\left(-4.75 \mathrm{~mm} \mathrm{year}^{-1}\right)$, Kuandian (-4.22 $\left.\mathrm{mm} \mathrm{year}^{-1}\right)$, and Dalian $\left(-3.27 \mathrm{~mm} \mathrm{year}^{-1}\right)$. Zhao et al. [24] reported that the greatest decrease of annual precipitation was $-3.19 \mathrm{~mm}_{\text {year }}^{-1}$ at Dalian station, with the small difference mainly attributed to different site densities (the first three stations were not included in their study) and different lengths for the precipitation series. Relative change of precipitation, defined as the absolute change divided by the mean precipitation, is also observed in our study. Relative precipitation does not change the order of the sorted precipitation sequence, and therefore both the $Z_{s}$ statistic of MK test and the significance of time series trend are consistent with the absolute precipitation. Figure 5(a) shows the spatial patterns of relative change in annual precipitation. A dramatic and widespread decrease in annual precipitation is observed, accounting for $11.5 \%$ of the mean annual precipitation over the 47-year period. The highest precipitation area, Liaodong Peninsula, has the greatest decrease (about 19.1\%), followed by
$12.5 \%$ in Northeastern Mountain and $10.4 \%$ in Central Plain, with the lowest reduction $(6.3 \%)$ taking place in the lowest precipitation area (Western Highland) (Figure 5(a)).

Abrupt behaviors in annual precipitation are further analyzed using the SMKRS test. The $u(t)$ and $u^{\prime}(t)$ statistics of the SMKRS test experience more than one nonsignificant change point for all stations, but only three significant change points are identified in about 1978 for Changtu, 1969 for Xifeng, and 1967 for Xiuyan, respectively (Figures 6(a)-6(c)). After that, a significant negative trend is detected for all the three stations, which is highly in agreement with the results of the MK test.

\subsection{Changes in Seasonal Precipitation. Seasonal precipitation} declines the greatest during the summer $\left(1.2 \mathrm{~mm}_{\text {year }}{ }^{-1}\right)$, followed by the autumn $\left(0.35 \mathrm{~mm}\right.$ year $\left.^{-1}\right)$ and the spring $\left(0.09 \mathrm{~mm}\right.$ year $\left.^{-1}\right)$, with a weak increase $\left(0.02 \mathrm{~mm} \mathrm{year}^{-1}\right)$ in winter, while the relative precipitation decreases the highest by $15.2 \%$ in autumn over the 47 -year period, followed by $15.2 \%$ in summer, $12.0 \%$ in spring, with $9.1 \%$ increase in winter precipitation, as a percentage of the corresponding mean seasonal precipitation (Figures 5 and 6). The magnitude of the trends for seasonal precipitation varies dramatically both seasonally and spatially (Figures 4(b)-4(e)). The spatial distribution of spring rainfall shows a negative trend for $63 \%$ of meteorological stations mainly located in the Central Plain subregion, while $37 \%$ stations exhibit a positive trend in parts of Northeastern Mountain and Liaodong Peninsula and most of the Western Highland (Figure 4(b)). There is no significant trend identified in spring precipitation for any of the 49 meteorological stations. Despite the difference in precipitation amounts, the relative precipitation is in good conformity with the absolute precipitation in the spatial distribution (Figures 4(b) and 5(b)).

Summer is the principal rainy season, accounting for $65 \%$ of annual precipitation. Forty-five of the stations (92\%) experience a negative trend in summer rainfall (Table 1), including all of Northeastern Mountain, Liaodong Peninsula, and Western Highland and the majority of Central Plain (Figure 4(c)). Three precipitation series are detected to have a significant negative trend. Significant negative trends are found in the Dalian station and the other two stations (Xiuyan and Zhuanghe) located at the east part of Liaodong Peninsula, where both the highest annual and summer precipitation 

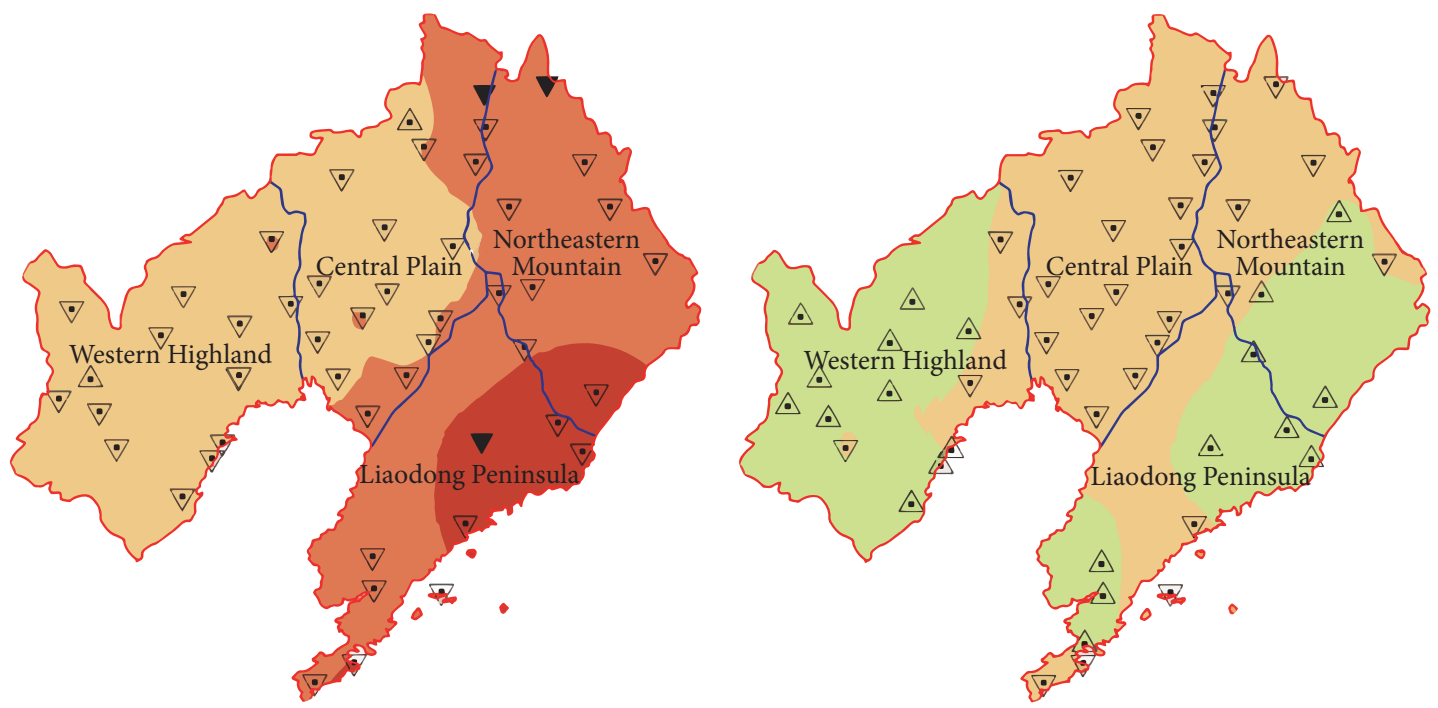

TSA trend magnitude ( $\mathrm{mm} /$ year)

TSA trend magnitude ( $\mathrm{mm} /$ year)

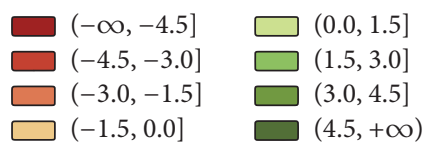

MK trend test
- Significant uptrend - Uptrend
$\checkmark$ Downtrend
$\nabla$ Significant downtrend

(a)

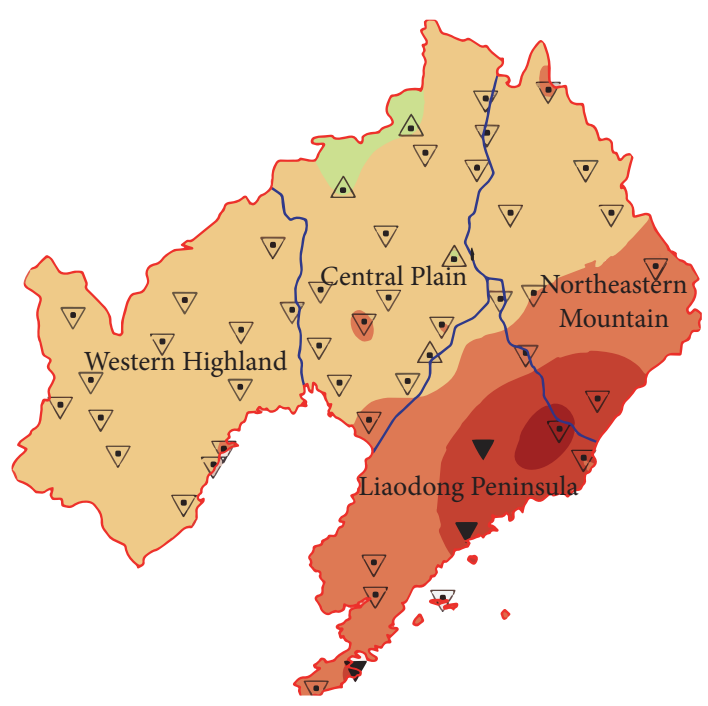

TSA trend magnitude ( $\mathrm{mm} /$ year)

$$
\begin{array}{ll}
\square(-\infty,-4.5] & \square(0.0,1.5] \\
\square(-4.5,-3.0] & \square(1.5,3.0] \\
\square(-3.0,-1.5] & \square(3.0,4.5] \\
\square(-1.5,0.0] & \square .5,+\infty)
\end{array}
$$

MK trend test
- Significant uptrend
$\checkmark$ Downtrend
- Uptrend
$\checkmark$ Significant downtrend

(c)

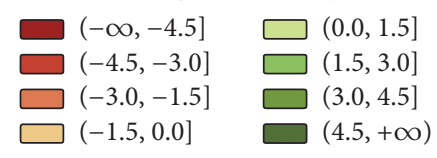

MK trend test
\ Significant uptrend
$\checkmark$ Downtrend
- Uptrend
$\nabla$ Significant downtrend

(b)

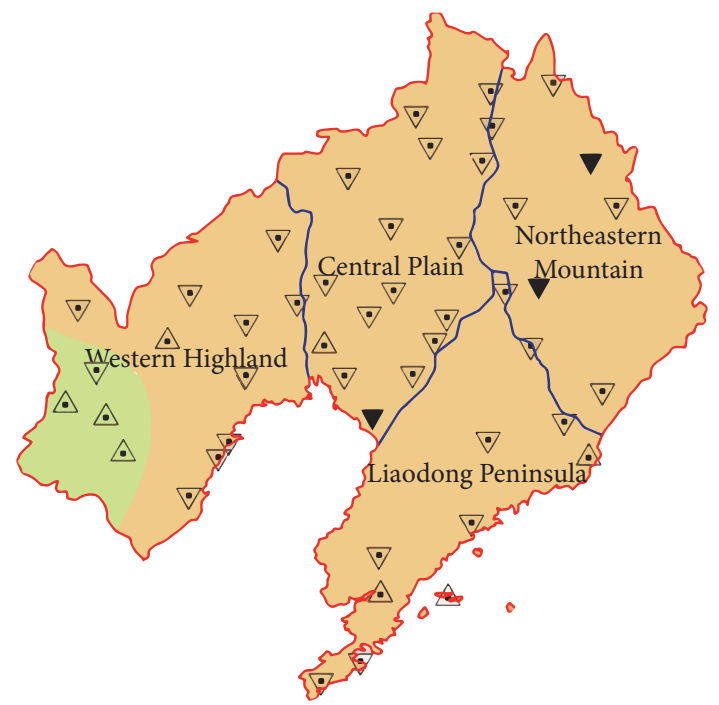

TSA trend magnitude ( $\mathrm{mm} /$ year)

$$
\begin{array}{ll}
\square(-\infty,-4.5] & \square(0.0,1.5] \\
\square(-4.5,-3.0] & \square(1.5,3.0] \\
\square(-3.0,-1.5] & \square(3.0,4.5] \\
\square(-1.5,0.0] & \square(4.5,+\infty)
\end{array}
$$

MK trend test

A Significant uptrend

$\checkmark$ Downtrend

- Uptrend

$\nabla$ Significant downtrend

Figure 4: Continued. 


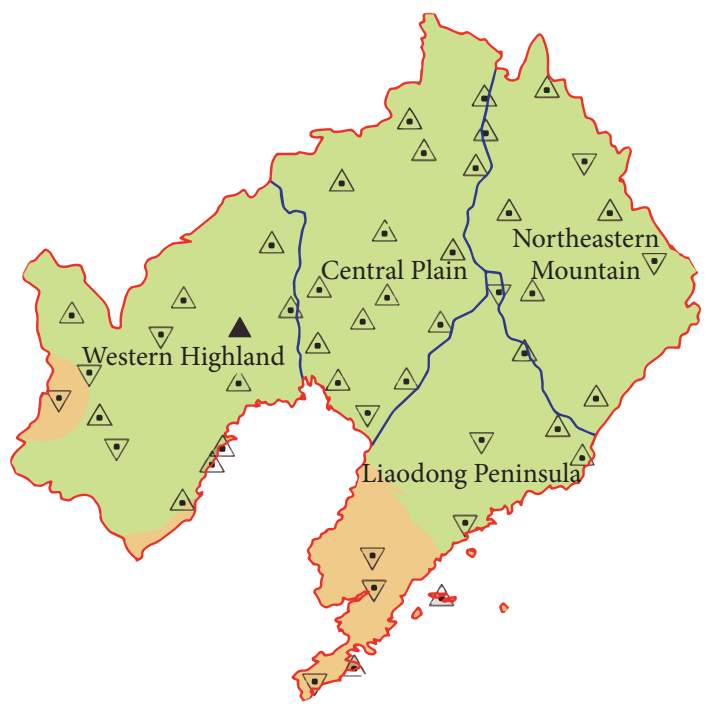

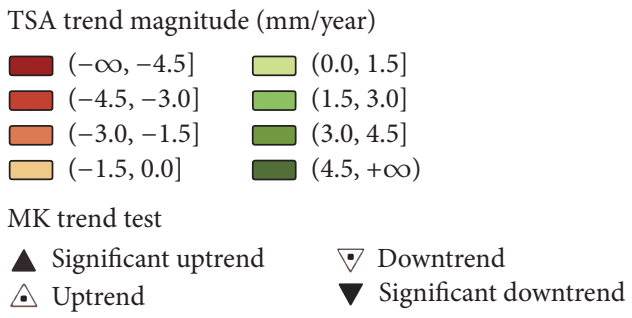

(e)

FIGURE 4: Spatial distribution patterns of precipitation trends and the significance for 49 selected meteorological stations at annual and seasonal time scales: (a) annual, (b) spring, (c) summer, (d) autumn, and (e) winter precipitation. TSA indicates the Theil-Sen approach.

areas of Liaoning are concentrated. The significant absolute decreases cause the highest three relative precipitation declines in Dalian (43.2\%), Xiuyan (37.7\%), and Zhuanghe (36.2\%) over the 47-year period (Figure 5(c)). The magnitude of summer precipitation trends is $-1.2 \mathrm{~mm}$ year $^{-1}$ on average (15.2\% reduction) and gradually declines from the southeast $\left(-5.57 \mathrm{~mm}\right.$ year $\left.^{-1}\right)$ to the northwest $\left(0.34 \mathrm{~mm} \mathrm{year}^{-1}\right)$ (see Figure 4(c)). The similar results for annual and summer precipitation, including the two precipitation series occurring from 1960 to 2006 (Figure 2(a)), are largely due to the fact that annual precipitation change primarily comprises the change and occurrence of summer precipitation as reported by Liang et al. [14]. Graphical results of the SMKRS test clearly identify a progressive series and a backward series across each other (in 1968 at Dalian, 1967 at Xiuyan, and 1968 at Zhuanghe) and then diverge and exceed the $95 \%$ confidence limit, suggesting a significant negative trend for the three stations with the starting point of the trend being in the 1960s.

A province-wide negative trend is also observed for autumn precipitation. Forty-one (84\%) of the stations exhibit a negative trend. The magnitude of the autumn precipitation trends, varying between -1.58 and $0.48 \mathrm{~mm} \mathrm{year}^{-1}$, is considerably lower when comparing with the summer precipitation, while the relative change $(15.7 \%$ decline) is comparable to the decline $(15.2 \%)$ in summer precipitation (Figure 5(d)).
The result suggests that Liaoning may experience a great potential impacts in the autumn, despite the relatively small decline in absolute precipitation. Three stations, Benxixian, Qingyuan, and Yingkou, experience a significant decline, and the significant change points identified are in about 1977, 1973, and 1974, respectively.

Winter is the lowest season in precipitation amount $(2.7 \%$ of annual precipitation). The trend amplitude is relatively stable across the entire Liaoning and ranges from -0.33 to $0.30 \mathrm{~mm}_{\text {year }}{ }^{-1}$, while the relative change dramatically varies from the $63 \%$ increase in the northeast to the $58 \%$ decline in the southeast of Liaodong Peninsula (Figure 5(e)). The majority of the stations $(73 \%)$ are dominated by a weak increase trend in winter precipitation, with the other $27 \%$ stations showing a nonsignificant decrease (Figure 4(e)). One location where a significant increase occurred is observed in Yixian station. The precipitation series begins to increase in 1976 and continues increasing until 2006 (Figure 6(j) and Table 2).

3.3. Regional Trend Analysis of Regional Precipitation. Table 3 shows Regional Kendall slopes for the regional precipitation for Liaoning and its four subregions at both annual and seasonal time scales. The prevailing provincewide negative trends in annual $\left(-1.51 \mathrm{~mm}\right.$ year $\left.^{-1}\right)$, summer 

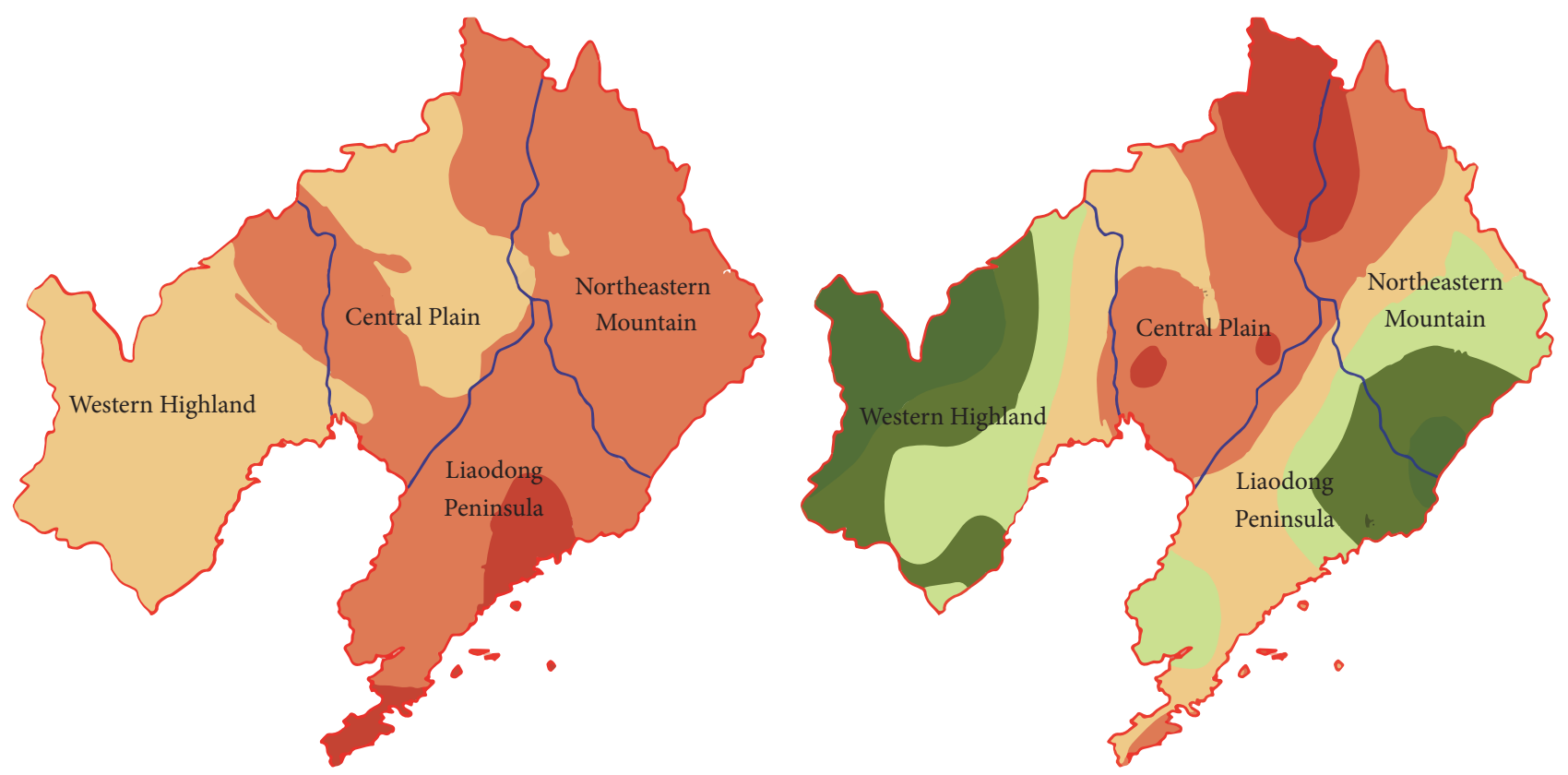

TSA trend magnitude (\%)

$$
\begin{array}{ll}
\square(-\infty,-30.0] & \square(0.0,10.0] \\
(-30.0,-20.0] & \square(10.0,20.0] \\
(-20.0,-10.0] & \square(20.0,+\infty)
\end{array}
$$

(a)

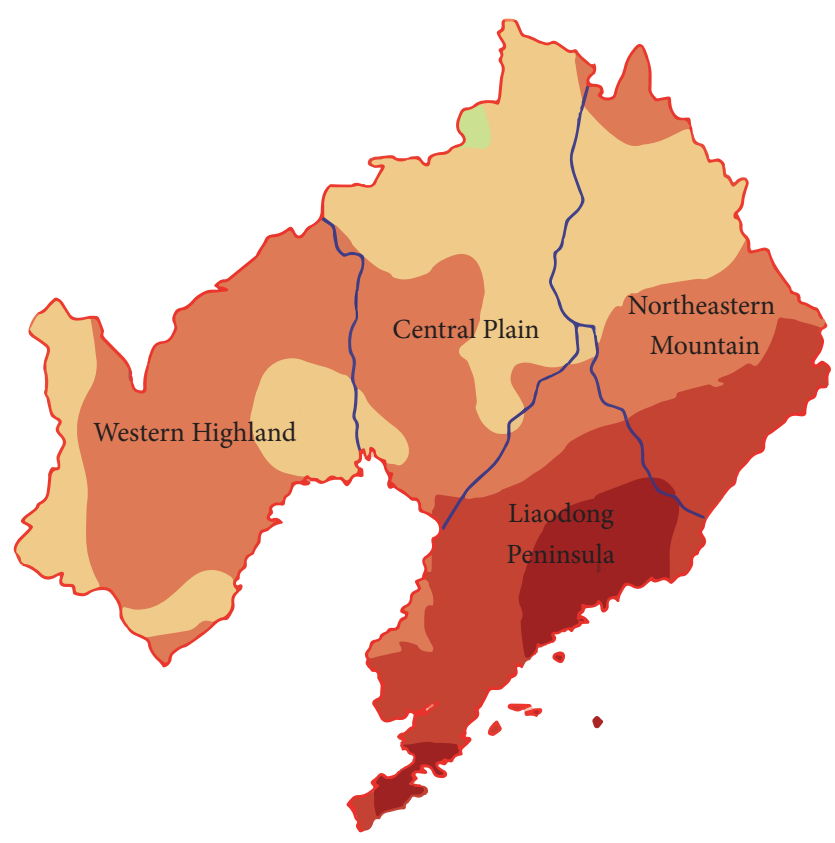

TSA trend magnitude (\%)

$$
\begin{array}{ll}
\left(_{(-\infty,-30.0]}\right. & \square(0.0,10.0] \\
\left(_{(-20.0,-10.0]}\right. & \square(10.0,20.0] \\
(20.0,+\infty)
\end{array}
$$

(c)
TSA trend magnitude (\%)

$$
\begin{array}{ll}
\square(-\infty,-30.0] & \square(0.0,10.0] \\
(-30.0,-20.0] & \square(10.0,20.0] \\
\square(-20.0,-10.0] & \square(20.0,+\infty) \\
\square(-10.0,0.0] &
\end{array}
$$

(b)

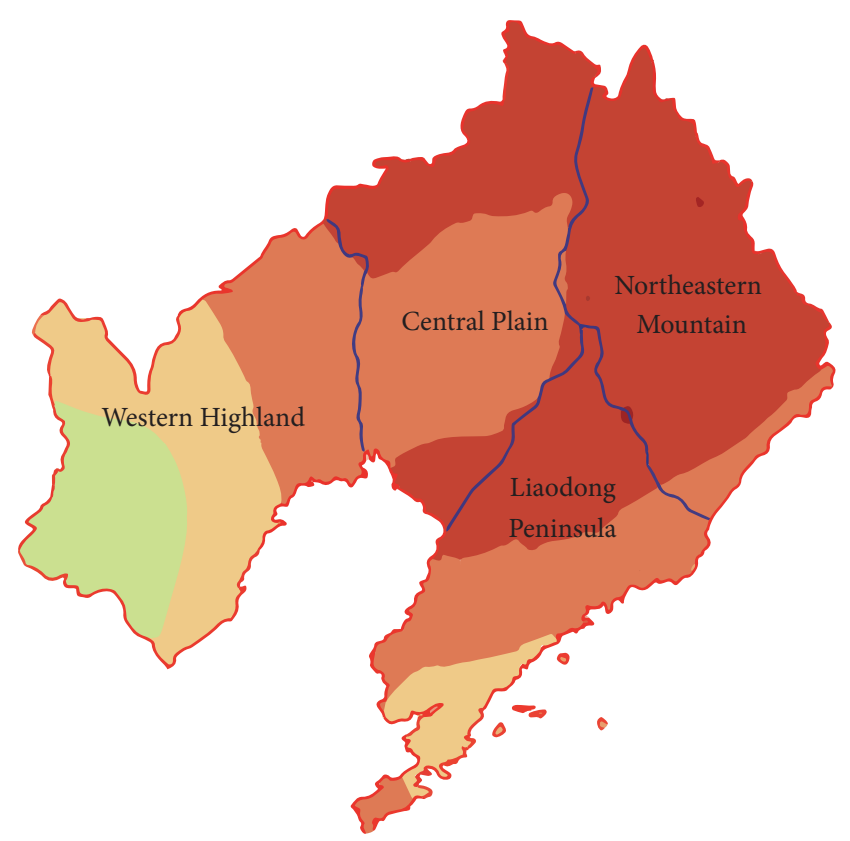

TSA trend magnitude (\%)

$$
\begin{array}{ll}
\text { (- } \left._{(-30.0,-30.0]}-20.0\right] & \square(0.0,10.0] \\
\left(_{(-20.0,-10.0]}\right. & \square(20.0,20.0] \\
\square(-10.0,0.0] &
\end{array}
$$

(d)

Figure 5: Continued. 


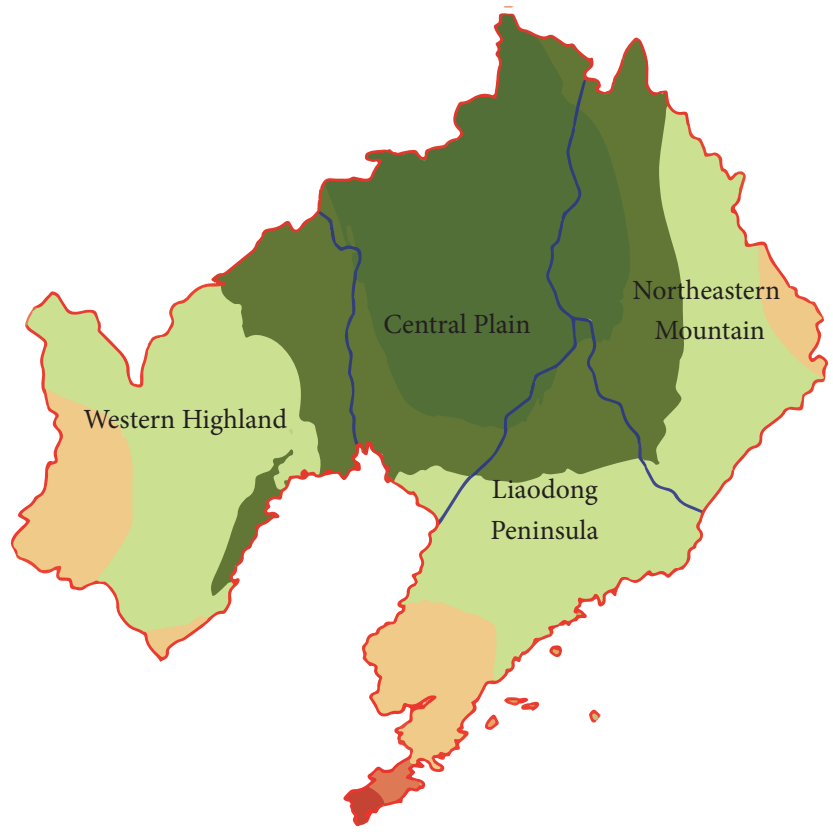

$\begin{array}{ll}\text { TSA trend magnitude (\%) } & \\ \begin{array}{ll}(-\infty,-30.0] & \\ (-30.0,-20.0] & \\ (0.0,10.0] \\ (-20.0,-10.0] & \square \\ (20.0,20.0] \\ (-10.0,0.0] & \end{array} \\ \square(-\infty)\end{array}$

(e)

FIGURE 5: Spatial distribution patterns of relative precipitation variation (as a percentage of the mean annual or seasonal precipitation) over the 47-year period at annual and seasonal time scales: (a) annual, (b) spring, (c) summer, (d) autumn, and (e) winter precipitation. Theil-Sen's estimator (TSA, Theil-Sen approach) is used to quantify the magnitude of trends.

TABle 2: Analysis for significant trends using sequential MannKendall rank statistic test.

\begin{tabular}{lccc}
\hline \multirow{2}{*}{ Station names } & \multirow{2}{*}{ Time scale } & \multicolumn{2}{c}{ Abrupt behavior } \\
& & Beginning year & Trend \\
\hline Changtu & Annual & 1978 & $\downarrow$ \\
Xifeng & Annual & 1969 & $\downarrow$ \\
Xiuyan & Annual & 1967 & $\downarrow$ \\
Dalian & Summer & 1968 & $\downarrow$ \\
Xiuyan & Summer & 1967 & $\downarrow$ \\
Zhuanghe & Summer & 1968 & $\downarrow$ \\
Benxixian & Autumn & 1977 & $\downarrow$ \\
Qingyuan & Autumn & 1973 & $\downarrow$ \\
Yingkou & Autumn & 1974 & $\downarrow$ \\
Yixian & Winter & 1976 & $\uparrow$ \\
\hline
\end{tabular}

$\left(-1.20 \mathrm{~mm}\right.$ year $\left.^{-1}\right)$, autumn $\left(-0.35 \mathrm{~mm} \mathrm{year}^{-1}\right)$, and spring $\left(-0.09 \mathrm{~mm}^{-1}\right.$ year $\left.^{-1}\right)$ precipitation are detected, which are highly consistent with the results from the site-specific analysis. Furthermore, annual, summer, and autumn precipitation have consistent patterns of significant decreasing regional trends. The greatest negative regional trends in annual precipitation among the four subregions are identified in Liaodong Peninsula $\left(-2.87 \mathrm{~mm}_{\text {year }}{ }^{-1}\right)$, followed by Northeastern Mountain ( $-2.14 \mathrm{~mm}$ year $\left.^{-1}\right)$, Central Plain $\left(-1.33 \mathrm{~mm}\right.$ year $\left.^{-1}\right)$, and Western Highland $(-0.70 \mathrm{~mm}$ year $\left.^{-1}\right)$. Liaodong Peninsula, Northeastern Mountain, and Central Plain show consistent patterns of significant negative regional trends in annual, summer, and autumn precipitation, similar to annual precipitation for Liaoning province. The regional Kendall Test detects more significant declines in regional precipitation at both annual and seasonal time scales compared to the MK test at a site scale. This is because trends of many individual locations in a region that occur in the same direction provide some evidences toward a significant regional trend, even if there is insufficient evidence of trend at site-specific stations [35]. Western Highland, the highest arid subregion, is the most stable region among the four subregions. A significant change for Western Highland subregion is only detected in summer precipitation $\left(-0.93 \mathrm{~mm}_{\text {year }}{ }^{-1}\right)$ with a $12.4 \%$ relative decline over the 47 years. Summer experiences a great decline among the seasonal precipitations, while autumn, comparable to summer, numerically decreases the greatest in the relative precipitation, and both show a significant and consistent decline at the province scale. 


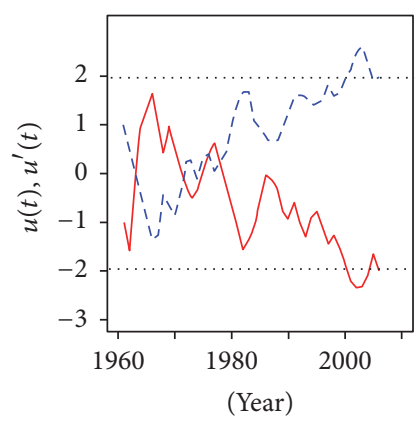

…. Lim --- $u^{\prime}(t)$

(a)

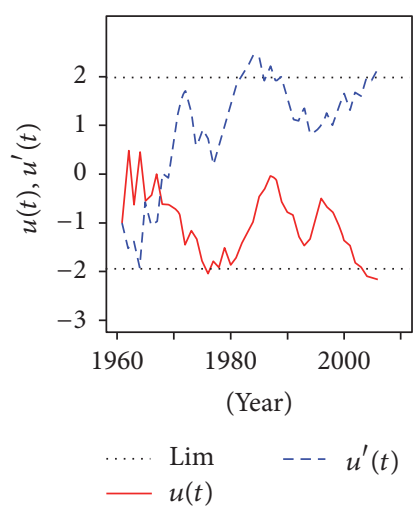

(e)

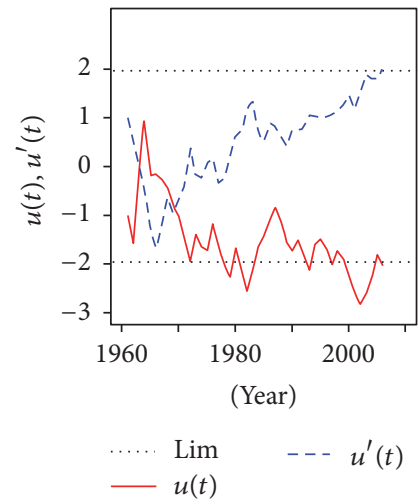

(b)

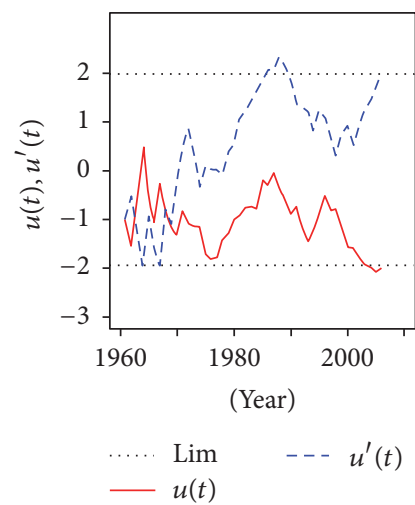

(f)

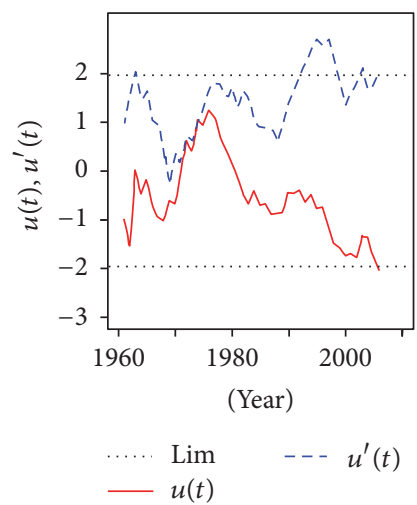

(i)

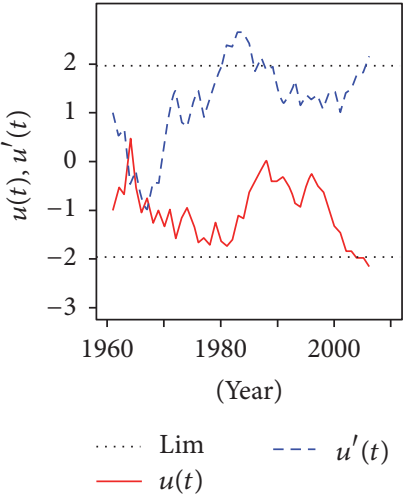

(c)

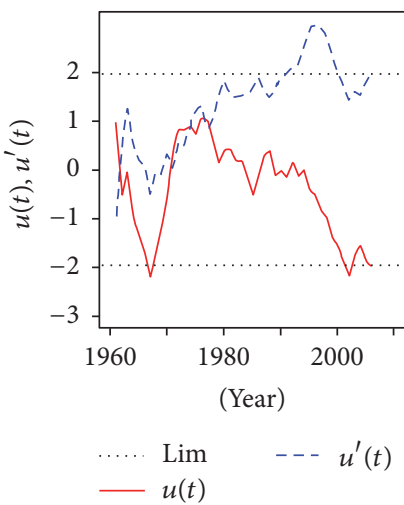

(g)

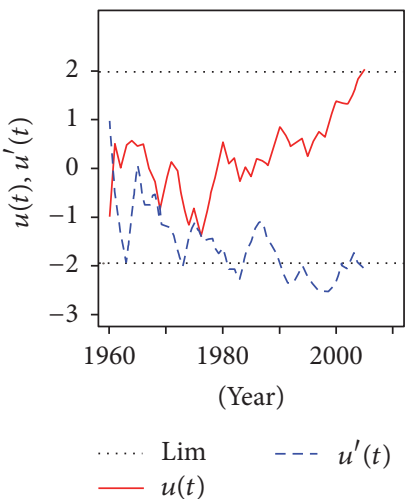

(j)

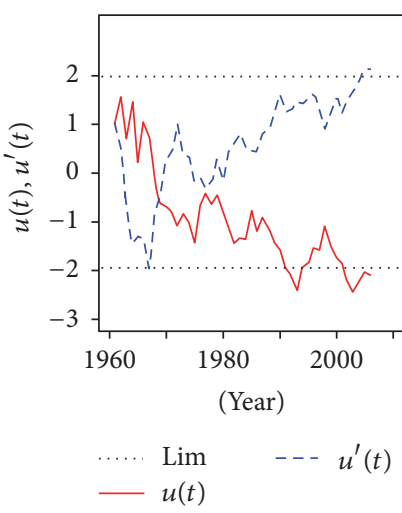

(d)

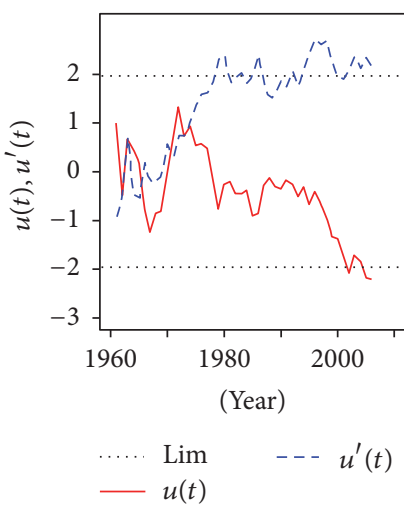

(h)

Figure 6: Graphical representation of the forward series $u(t)$ and backward series $u^{\prime}(t)$ of Sequential Mann-Kendall Rank Statistic test: (a) Changtu annual precipitation, (b) Xifeng annual precipitation, (c) Xiuyan annual precipitation, (d) Dalian summer precipitation, (e) Xiuyan summer precipitation, (f) Zhuanghe summer precipitation, (g) Benxixian autumn precipitation, (h) Qingyuan autumn precipitation, (i) Yingkou autumn precipitation, and (j) Yixian winter precipitation. Two limit lines are the upper and lower critical values $( \pm 1.96, p=0.05)$, respectively. Sequential Mann-Kendall Rank Statistic test is applied only if changing trend of annual and seasonal precipitation series is statistically significant at $p=0.05$ by using Mann-Kendall test.

3.4. Cycle Analysis of Regional Precipitation. The real parts of the wavelet transformation coefficients describe the fluctuation characteristics of annual precipitation for the four subregions and for the Liaoning province (Figures 7 (a), 7(d), $7(\mathrm{~g}), 7(\mathrm{j})$, and $7(\mathrm{~m}))$. Solid contours represent the positive phase (coefficients of real part are greater than 0 ) while dotted contours indicate a negative phase. Figures 7(b), 7(e), $7(\mathrm{~h}), 7(\mathrm{k})$, and $7(\mathrm{n})$ show wavelet transformation variances at different time scales. Wavelet variance reflects the energy of fluctuations over time [40]. Four primary cycles with fluctuating patterns are detected at four time scales $(3-5,10$ $11,20-23$, and 31.2 years) for all four subregions, and for 
TABLE 3: Regional Kendall slopes for Liaoning precipitation and its four subregions at different time scales.

\begin{tabular}{|c|c|c|c|c|c|}
\hline Time scale & Liaodong Peninsula & Northeastern Mountain & Western Highland & Central Plain & Liaoning \\
\hline Spring & $0.03^{\mathrm{ns}}$ & $-0.17^{\mathrm{ns}}$ & $0.15^{\mathrm{ns}}$ & $-0.37^{* *}$ & $-0.09^{\mathrm{ns}}$ \\
\hline Summer & $-2.59^{* *}$ & $-1.28^{*}$ & $-0.93^{* *}$ & $-0.82^{*}$ & $-1.20^{* *}$ \\
\hline Autumn & $-0.39^{*}$ & $-0.80^{* *}$ & $-0.08^{\mathrm{ns}}$ & $-0.45^{* *}$ & $-0.35^{* *}$ \\
\hline Winter & $-0.07^{\mathrm{ns}}$ & $0.03^{\mathrm{ns}}$ & $-0.01^{\mathrm{ns}}$ & $0.03^{\mathrm{ns}}$ & $0.02^{\mathrm{ns}}$ \\
\hline Annual & $-2.87^{* *}$ & $-2.14^{* *}$ & $-0.70^{\mathrm{ns}}$ & $-1.33^{* *}$ & $-1.51^{* *}$ \\
\hline
\end{tabular}

Regional Kendall test was used to test the consistent pattern of regional precipitation trend. Data followed by “**” and “*” indicate that significant regional trends are detected at the $99 \%$ and $95 \%$ probability levels at the regional scales, respectively.

Liaoning. The highest peaks of each wavelet variance curve indicate that the dominant periodicities of the four subregional precipitations, Liaodong Peninsula, Northeastern Mountain, Western Highland, and Central Plain, and Liaoning are 11.0, 10.4, 3.7, 10.4, and 10.4 years, respectively, meaning that the majority (80\%) of Liaoning and its subregions are impacted the greatest by the second cycles (10-11) among the four time scales (Figures 7(b), 7(e), 7(k), and 7(n)). The only exception is Western Highland, whose dominant periodicity is 3.7 years but immediately followed by a 9.8-year cycle (Figure $7(\mathrm{~h})$ ). It is interesting to note that the longest precipitation periodicities for Liaoning region and its different subregions are completely consistent, and these periodicities (31.2 years) are similar to the 35-year periodicities reported by Li et al. [40], who indicated that the main periodic series of long-term precipitation data (286 years) in Beijing were 85-, 35-, and 21-year periodic events. Twenty-one-year periodic events are also observed in our third cycles of 20-23 years.

The modulus square time-frequency distribution reflects the signal strength at different time scales in the entire time domain (Figures 7(c), 7(f), 7(i), 7(l), and 7(o)). With the exception of the Western Highland subregion, the strongest signals for the other three subregions and Liaoning province are almost all at 10-11 years time scales, centers around 1989-1992, and covers throughout the entire time domain. The shortest distinct periodicity (3-5 years) covers parts of the 1960 to 1980 years time domain, which does not show persistent effects on rainfall. In the Western Highland, the strongest signal is observed around 1993 with a 3-5-year time scales and primarily covers over the period 1985-2005.

The causes of long-term variations of the precipitation are complex and may vary depending on the time scale investigated. Correlations between Liaoning regional precipitation, sunspot number, East Asian Summer Monsoon (EASM), and Global-SST ENSO index (ENSO) are analyzed at the four primary cycles $(3-5,10-11,20-25$, and 30-33) during the observed period. In an attempt to identify possible links between them, the Pearson correlation method is used to explain the relationships using the extracted wavelet coefficients at the same or similar time scale. The strongest cycle of sunspot number is detected at 10-11-year time scale, which has a significantly negative correlation with Liaoning annual precipitation at the time scale of the 10-11 dominant periodicity (Table 4$)$. The high correlation coefficient of $-0.97(p<0.01)$ indicates that sunspot number explains $94.1 \%$ amount of 10-11 periodic variation of the extracted wavelet coefficients of Liaoning annual precipitation at the
TABLE 4: Correlations between Liaoning annual precipitation, sunspot number, East Asian Summer Monsoon (EASM), and Global-SST ENSO index (ENSO) at the four primary cycles (3-5, $10-11,20-25$, and 30-33) during the observed period.

\begin{tabular}{lccc}
\hline Time scale & Sunspot number & EASM & ENSO \\
\hline $3-5$ & -0.03 & $/$ & -0.05 \\
$10-11$ & $-0.97^{* *}$ & $0.54^{* *}$ & -0.06 \\
$20-25$ & $/$ & -0.06 & $/$ \\
$30-33$ & $/$ & $0.36^{*}$ & $0.31^{*}$ \\
\hline
\end{tabular}

The Pearson correlation method was used to explain linear relationships between Liaoning regional precipitation, sunspot number, EASM, and ENSO. $*, * *$ denote passing correlation at $99 \%$ and $95 \%$ confidence levels, respectively. / indicates that there are no periodic signals detected at the specified time scale.

10-11 times scale, which is highly supported by synchronized and negative phase relationship between Liaoning annual precipitation and sunspot number (Figure 8(a)). In contrast, the EASM also shows a significantly positive correlation with Liaoning annual precipitation at the 10-11-year time scale, with a relatively low coefficient of $0.54(p<0.01)$, indicating that they are basically in phase (Figure $8(\mathrm{~b})$ ). These results, therefore, suggest that the 10-11 periodic variation of Liaoning annual precipitation is negatively associated with sunspot activity $(p<0.01)$ and positively associated with the EASM $(p<0.01)$. However, the $30-33$ periodic variation of Liaoning annual precipitation is positively associated with both the EASM and the ENSO at the 30-33-year time scale; the correlation coefficients are 0.36 for the EASM and 0.31 for the ENSO, both passing the $p<0.05$ significant level (Table 4). The causes for 3-5- and 20-23-year periodic variation for Liaoning annual precipitation are not clear.

\section{Conclusions}

In this paper, we systematically explored the trend and cycle characteristics of Liaoning province precipitation at different time and spatial scales. Seasonal precipitation declines the greatest during the summer $\left(1.2 \mathrm{~mm} \mathrm{year}^{-1}\right)$, followed by autumn $\left(0.35 \mathrm{~mm} \mathrm{year}^{-1}\right)$, and spring $\left(0.09 \mathrm{~mm} \mathrm{year}^{-1}\right)$, with a weak increase $\left(0.02 \mathrm{~mm}_{\text {year }}{ }^{-1}\right)$ in winter, while the relative precipitation decreases the highest by $15.2 \%$ in autumn, followed by $15.2 \%$ in summer, $12.0 \%$ in spring, with $9.1 \%$ increase in winter precipitation over the 47-year period. Province-wide negative trends have taken place at $96 \%$ of 


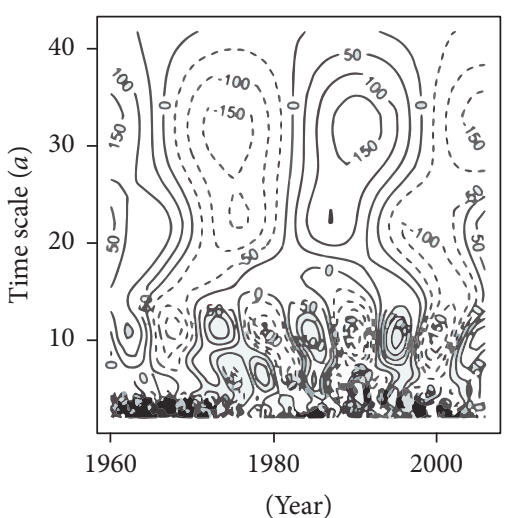

(a)

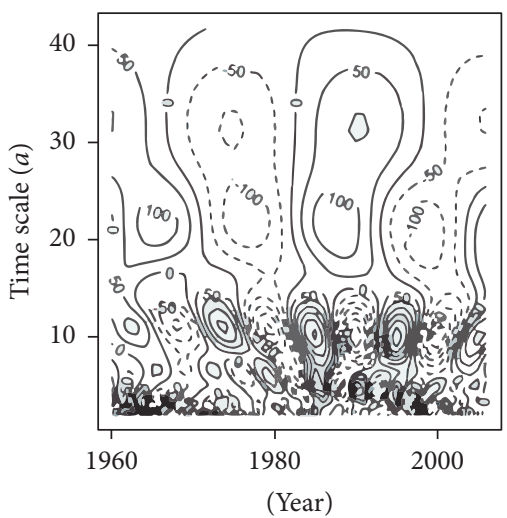

(d)

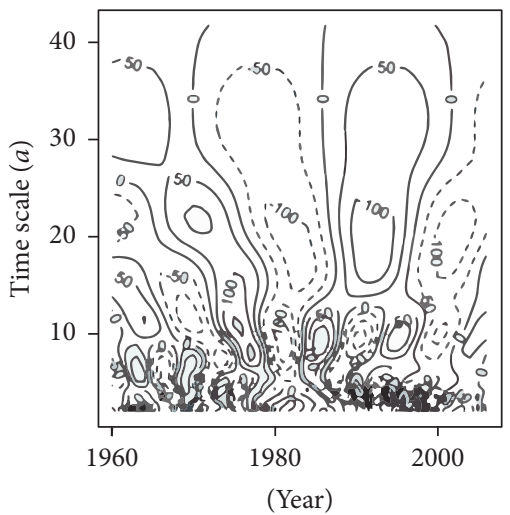

(g)

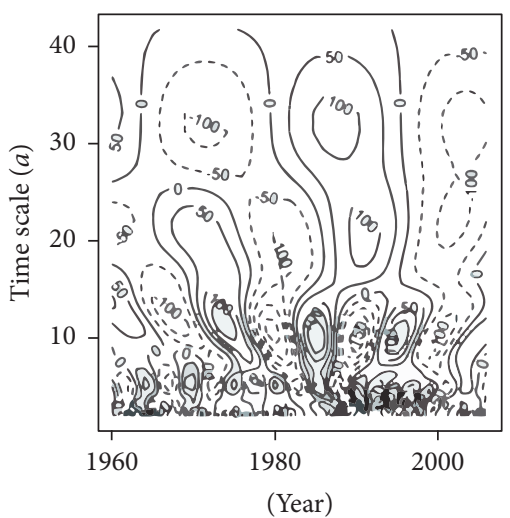

(j)

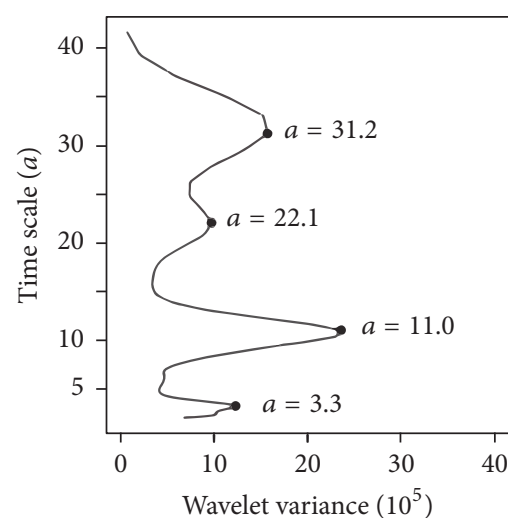

(b)

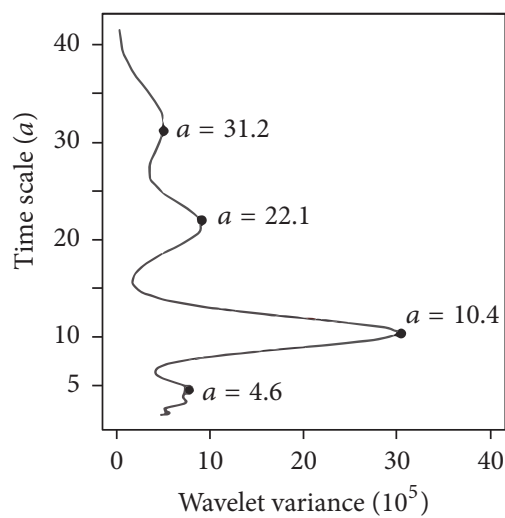

(e)

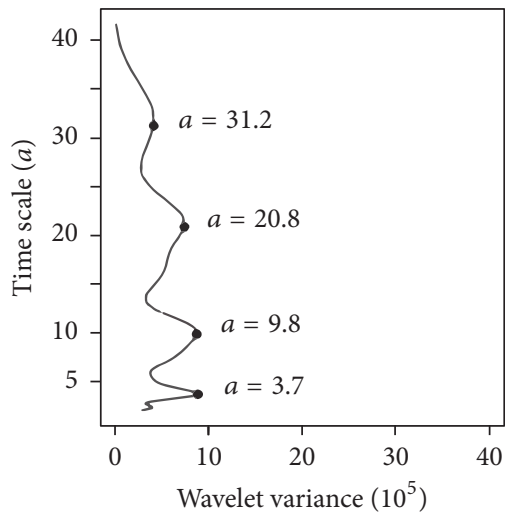

(h)

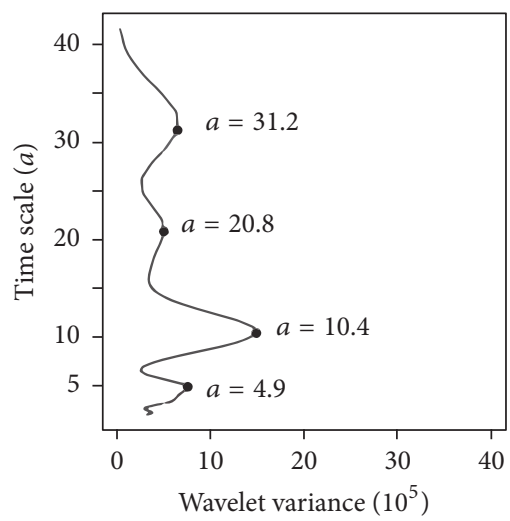

(k)

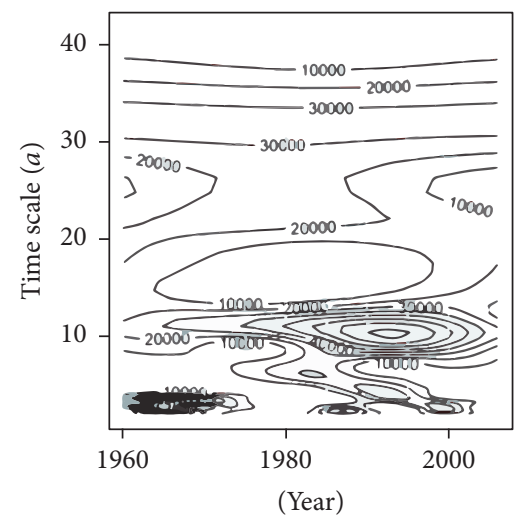

(c)

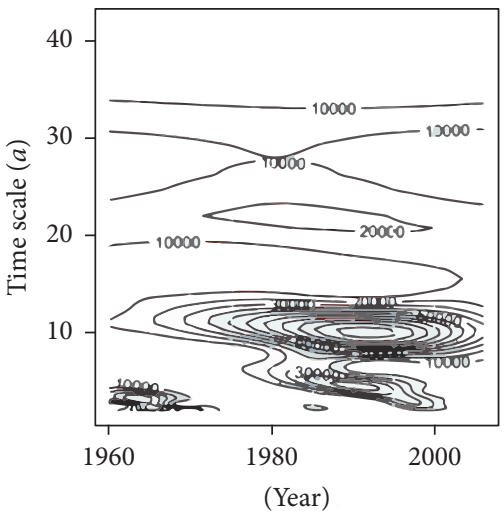

(f)

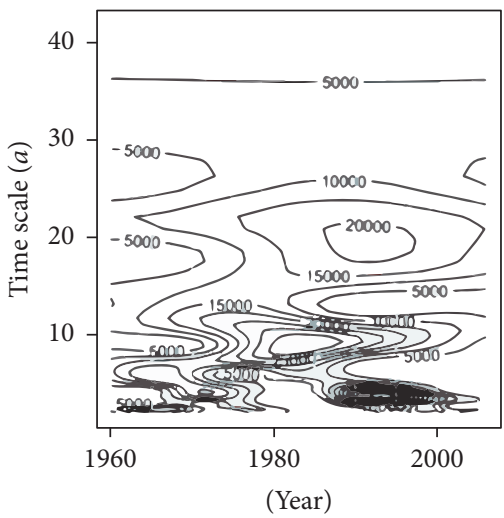

(i)

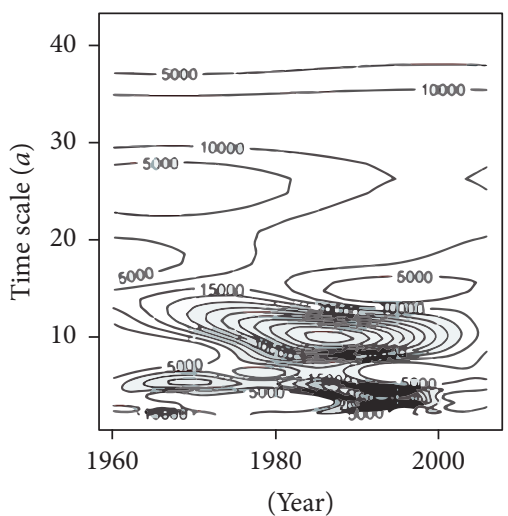

(l)

Figure 7: Continued. 


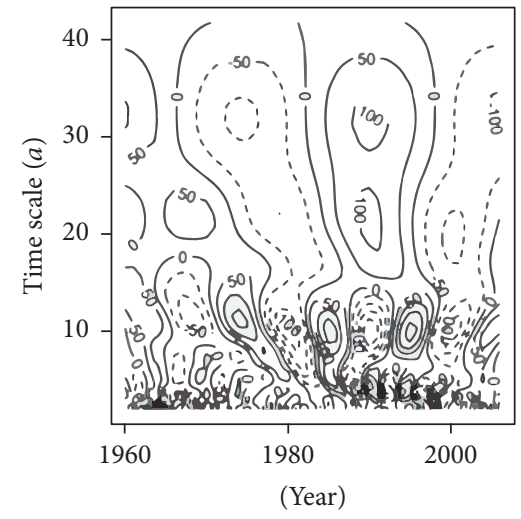

(m)

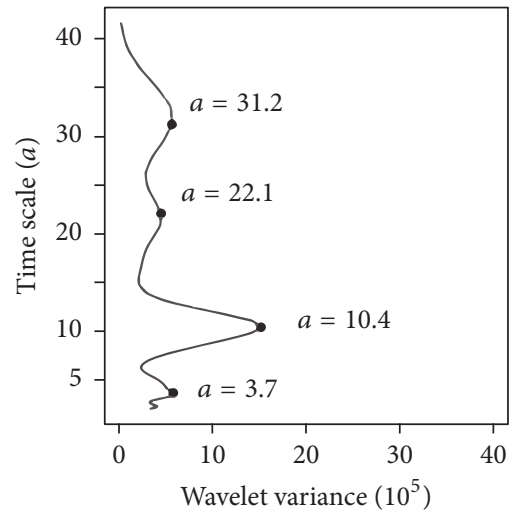

(n)

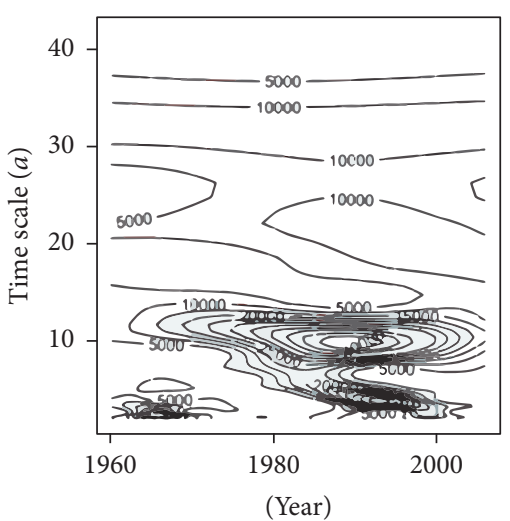

(o)

Figure 7: Real part (a, d, g, j, and m), wavelet variance (b, e, h, k, and n), and modulus square (c, f, i, l, and o) of wavelet transformation coefficients for annual precipitation in four subregions (Liaodong Peninsula, (a-c); Northeastern Mountain, (d-f); Western Highland, (g-i); and Central Plain $(\mathrm{j}-\mathrm{l}))$ and Liaoning $(\mathrm{m}-\mathrm{o})$ by using the Morlet Wavelet analysis.

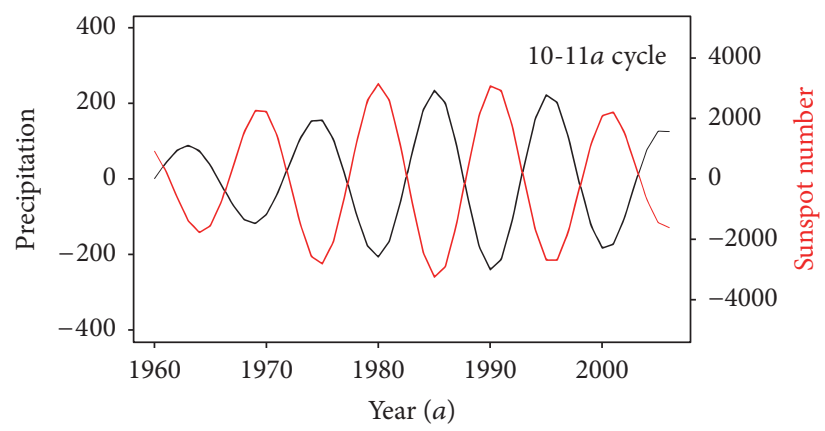

(a)

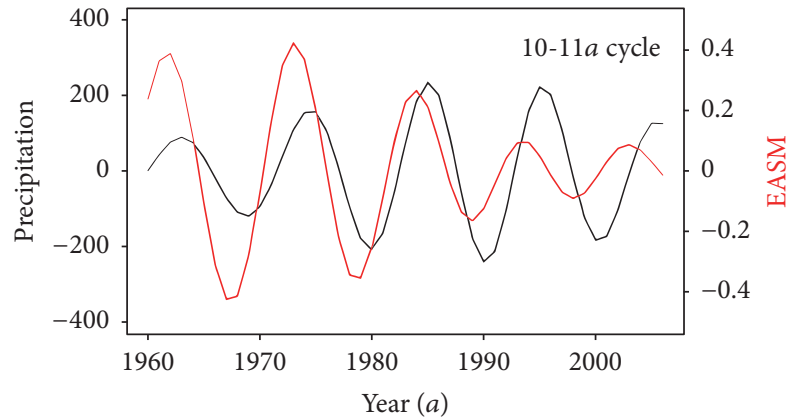

(b)

FIGURE 8: Phase relationship between Liaoning annual precipitation and sunspot number (a), Liaoning annual precipitation and East Asian Summer Monsoon (EASM) (b) at a 10-11 years time scale.

meteorological stations for annual precipitation, followed by $92 \%, 84 \%, 63 \%$, and $27 \%$ at a site scale during the summer, autumn, spring, and winter, respectively. Three stations for each of the annual, summer, and autumn periods show a significant negative trend while one station during the winter shows a significant positive trend. Regional trend analysis confirms the province-wide decrease in annual, summer, autumn, spring precipitation for Liaoning province. Significant negative trends are consistently observed for three of its four subregions, especially for summer, autumn, and annual precipitation.

These province-wide negative trends are consistent with the results obtained using the Regional Kendall Test. However, in contrast to the results of site-specific analyses and the previous studies $[14,17,50]$, our results reveal that precipitation from a regional view shows more significant and frequent declines in Liaoning, as compared to the site-specific analyses. Regional precipitation for a specific subregion (e.g., summer precipitation in Northeastern Mountain, Western Highland, and Central Plain in Figure 4(c)) where the significant trend is not detected for any individual station, nevertheless, shows a significant regional trend (Table 3), which is consistent with the findings reported by Helsel and Frans [35]. Widespread and consistent change in precipitation can be significant and can result in severe impacts on agriculture practices, water management policies, and even ecological conservation and agricultural development, even when changes are not statistically significant for any individual site within a subregion or region. Yue and Hashino [51] and Palizdan et al. [52] also reported that analysis using the regional trend analysis is superior to using the site-specific analysis, due to its better representation over a wide area, especially for global or regional phenomena such as climate change. These findings confirm the regional trend analysis using the Regional Kendall Test which is superior to site-specific analysis and imply a potentially increased risk for drought in Liaoning, especially for the summer and autumn seasons from a regional perspective. The significant province-wide decrease in precipitation $\left(-1.4 \mathrm{~mm}_{\text {year }}{ }^{-1}\right)$ in particular summer precipitation is likely linked with the weakened northeast Asian summer monsoon caused by warming sea surface temperature in the North Pacific and the shift of the Pacific Decadal Oscillation [14, 53, 54]. Another possible cause for decreased precipitation in Liaoning is the changes in arctic 
sea ice cover, which weakened water vapor transport [53]. In addition, during the East Asian Summer Monsoon, the increased Pacific high force gradually moves northwards and the moist southeast monsoon moves northwards along the west side of the high pressure. Coupled with the impact of the Eastern Mountain area of the Changbai mountain slope terrain, these monsoon activities result in significant differences in precipitation from Southeast to Northwest in Liaoning province [29].

Wavelet analysis suggests that there are four significant cycles of precipitation variability mainly at time scales of 3-5, 10-11, 20-23, and 31.2 years for each of the four subregions and for Liaoning province as a whole. Except for Western Highland, the strongest signals for the other three subregions and for Liaoning province are all at a 10-11-year time scales, center around 1989-1992, and cover throughout the entire time domain. The periodicity of monsoon is intra-annual and may be associated with sunspot, EASM, and ENSO activities, and many studies have reported that sunspot, EASM, and ENSO affect the monsoon precipitation [32, 53, 54]. Our results suggest that the 10-11 periodic variation identified in Liaoning annual precipitation is likely linked with sunspot and the EASM activities at the 10-11-year time scale, although the mechanism is still not understood. The significant precipitation-sunspot relation at the 10-11-year time scale is in agreement with previous studies [32]. And the significant precipitation-EASM relation is confirmed by the finding of Han et al. [53], who have reported that the EASM index is closely correlated with summer precipitation, in particular on the decadal time scale after detrending $(r=$ 0.74). Because the Mongolia low and East Asian trough is strengthened as trough activity increases over the Northeast China, a strong EASM generally accompanies strong ascending motion and a convergence of water vapor flux.

\section{Competing Interests}

The authors declare that there is no conflict of interests regarding the publication of this paper.

\section{Acknowledgments}

This study was financially supported by the Special Fund for Agro-Scientific Research in the Public Interest of China (201303125), the doctoral program of higher joint research fund funded project (20112103110007), and the Special Term Professor Fund Projects of Liaoning (Liao Education Bureau $\langle 2013\rangle)$.

\section{References}

[1] IPCC, Climate Change 2013. The Physical Science Basis. Working Group I Contribution to the Fifth Assessment Report of the Intergovernmental Panel on Climate Change, Cambridge University Press, Cambridge, UK, 2013.

[2] F. Ji, Z. Wu, J. Huang, and E. P. Chassignet, "Evolution of land surface air temperature trend," Nature Climate Change, vol. 4, no. 6, pp. 462-466, 2014.
[3] H. Deng, Y. Chen, X. Shi et al., "Dynamics of temperature and precipitation extremes and their spatial variation in the arid region of northwest China," Atmospheric Research, vol. 138, pp. 346-355, 2014.

[4] M. Hulme, "Estimating global changes in precipitation," Weather, vol. 50, no. 2, pp. 34-42, 1995.

[5] P. Vijaya Kumar, M. Bindi, A. Crisci, and G. Maracchi, "Detection of variations in precipitation at different time scales of twentieth century at three locations of Italy," Weather and Climate Extremes, vol. 2, pp. 7-15, 2013.

[6] C. Prigent, "Precipitation retrieval from space: an overview," Comptes Rendus-Geoscience, vol. 342, no. 4-5, pp. 380-389, 2010.

[7] G. T. Amanatidis, A. G. Paliatsos, C. C. Repapis, and J. G. Bartzis, "Decreasing precipitation trend in the Marathon area, Greece," International Journal of Climatology, vol. 13, no. 2, pp. 191-201, 1993.

[8] M. Gemmer, S. Becker, and T. Jiang, "Observed monthly precipitation trends in China 1951-2002," Theoretical and Applied Climatology, vol. 77, no. 1-2, pp. 39-45, 2004.

[9] Y. Fan, J. Li, Y. Zhong, B. Yang, and K. Guo, "Analysis on change trend of precipitation in yunnan dry-hot valley region based on rescaled range analysis method," Water Resources \& Power, vol. 26, no. 2, pp. 24-27, 2008.

[10] B. S. Some'e, A. Ezani, and H. Tabari, "Spatiotemporal trends and change point of precipitation in Iran," Atmospheric Research, vol. 113, pp. 1-12, 2012.

[11] Q. Zhang, V. P. Singh, J. Peng, Y. D. Chen, and J. Li, “Spatialtemporal changes of precipitation structure across the Pearl River basin, China," Journal of Water Resources Research, vol. 440, no. 11, pp. 113-122, 2012.

[12] M. Sayemuzzaman and M. K. Jha, "Seasonal and annual precipitation time series trend analysis in North Carolina, United States," Atmospheric Research, vol. 137, pp. 183-194, 2014.

[13] A. Dai, "Drought under global warming: a review," Wiley Interdisciplinary Reviews: Climate Change, vol. 2, no. 1, pp. 4565, 2011.

[14] L. Liang, L. Li, and Q. Liu, "Precipitation variability in Northeast China from 1961 to 2008," Journal of Hydrology, vol. 404, no. 1-2, pp. 67-76, 2011.

[15] Z. Chen, X. He, E. R. Cook et al., "Detecting dryness and wetness signals from tree-rings in Shenyang, Northeast China," Palaeogeography, Palaeoclimatology, Palaeoecology, vol. 302, no. 3-4, pp. 301-310, 2011.

[16] F. H. Sun, G. Y. Ren, C. Y. Zhao, and S. Y. Yang, "An analysis of temperature abnormal change in Northeast China and type underlying surface," Scientia Geographica Sinica, vol. 25, no. 2, pp. 167-171, 2005.

[17] Q. Q. Sun and J. M. Liu, "Temporal-spatial change of temperature and precipitation based on CAST in northeast China," Journal of Meteorology \& Environment, vol. 1/2014, pp. 13-31, 2014.

[18] H. E. Wei, B. U. Rencang, and Z. Xiong, "Characteristics of temperature and precipitation in Northeastern China from 1961 to 2005," Acta Ecologica Sinica, vol. 33, no. 2, pp. 519-531, 2013.

[19] Q. Zhang, P. Sun, V. P. Singh, and X. Chen, "Spatial-temporal precipitation changes (1956-2000) and their implications for agriculture in China," Global and Planetary Change, vol. 82-83, pp. 86-95, 2012.

[20] F. Yang and K.-M. Lau, "Trend and variability of China precipitation in spring and summer: linkage to sea-surface 
temperatures," International Journal of Climatology, vol. 24, no. 13, pp. 1625-1644, 2004.

[21] W. Qian and X. Lin, "Regional trends in recent precipitation indices in China," Meteorology and Atmospheric Physics, vol. 90, no. 3-4, pp. 193-207, 2005.

[22] P. Zhai, X. Zhang, H. Wan, and X. Pan, "Trends in total precipitation and frequency of daily precipitation extremes over China," Journal of Climate, vol. 18, no. 7, pp. 1096-1108, 2005.

[23] H.-Y. Yu, S.-H. Liu, Na. Zhao, D. Li, and Y.-T. Yu, "Characteristics of air temperature and precipitation in different regions of China from 1951 to 2009," Journal of Meteorology \& Environment, vol. 27, no. 4, pp. 1-11, 2011.

[24] D. Zhao, Z. Du, S. Wu, and Z. Wu, "Climate changes in northeastern China during last four decades," Chinese Geographical Science, vol. 17, no. 4, pp. 317-324, 2007.

[25] P. Gao, M. U. Xing-Min, F. Wang, and S. Y. Wang, "Trend analysis of precipitation in northeast China in recent 100 years," Journal of China Hydrology, vol. 30, no. 5, pp. 80-83, 2010.

[26] B. Wang, M. Zhang, J. Wei et al., "Changes in extreme precipitation over Northeast China, 1960-2011," Quaternary International, vol. 298, pp. 177-186, 2013.

[27] W. Y. Yang and Q. Q. Wang, "Analyses on circulation characteristics of precipitation anomalies in flood season of Liaoning," Plateau Meteorology, vol. 25, no. 5, pp. 969-974, 2006.

[28] L. U. Zhong-Yan, L. I. Chang-Qing, Z. P. Yuan, L. I. GuangXia, and F. Cai, "Extend methods of spatial distribution of temperature and precipitation based on GIS in Liaoning province," Chinese Journal of Agrometeorology, vol. 29, no. 1, pp. 90-32, 2008.

[29] Y. Wang, C. Zhao, and Y. Yang, "Climatic properties of summer precipitation of the last 45 years in Liaoning province," Heilongjiang Meteorology, vol. 23, no. 3, pp. 41-49, 2008.

[30] D. Yang, H. Liu, P. Guo, F. Zheng, and Q. Liu, "The precipitation changes in Liaoning during 1956-2008," Journal of Arid Land Resources Environment, vol. 25, no. 1, pp. 96-101, 2011.

[31] F. A. Leeming, Liaoning, 2015, http://www.britannica.com/ EBchecked/topic/338861/Liaoning.

[32] D. Liu, S. Guo, X. Chen, and Q. Shao, "Analysis of trends of annual and seasonal precipitation from 1956 to 2000 in Guangdong Province, China," Hydrological Sciences Journal, vol. 57, no. 2, pp. 358-369, 2012.

[33] R. Modarres and V. de Paulo Rodrigues da Silva, "Rainfall trends in arid and semi-arid regions of Iran," Journal of Arid Environments, vol. 70, no. 2, pp. 344-355, 2007.

[34] R. Modarres and A. Sarhadi, "Rainfall trends analysis of Iran in the last half of the twentieth century," Journal of Geophysical Research Atmospheres, vol. 114, no. 3, pp. 1065-1066, 2009.

[35] D. R. Helsel and L. M. Frans, "Regional Kendall test for trend," Environmental Science and Technology, vol. 40, no. 13, pp. 40664073, 2006

[36] H. B. Mann, "Nonparametric tests against trend," Econometrica, vol. 13, no. 3, pp. 245-259, 1945.

[37] E. J. Dietz and T. J. Killeen, "A nonparametric multivariate test for monotone trend with pharmaceutical applications," Journal of the American Statistical Association, vol. 76, no. 373, pp. 169174, 1981.

[38] H. Tabari and M.-B. Aghajanloo, “Temporal pattern of aridity index in Iran with considering precipitation and evapotranspiration trends," International Journal of Climatology, vol. 33, no. 2, pp. 396-409, 2013.
[39] Z. X. Xu, K. Takeuchi, and H. Ishidaira, "Monotonic trend and step changes in Japanese precipitation," Journal of Hydrology, vol. 279, no. 1-4, pp. 144-150, 2003.

[40] M. Li, J. Xia, Z. Chen, D. Meng, and C. Xu, "Variation analysis of precipitation during past 286 years in Beijing area, China, using non-parametric test and wavelet analysis," Hydrological Processes, vol. 27, no. 20, pp. 2934-2943, 2013.

[41] C. Torrence and G. P. Compo, "A practical guide to wavelet analysis," Bulletin of the American Meteorological Society, vol. 79, no. 1, pp. 61-79, 1997.

[42] M. Farge, "Wavelet transforms and their applications to turbulence," Annual Review of Fluid Mechanics, vol. 24, no. 1, pp. 395458, 1992.

[43] R. Sneyers, "On the statistical analysis of series of observations," Journal of Biological Chemistry, vol. 258, no. 22, pp. 1368013684, 1991.

[44] T. Partal and E. Kahya, "Trend analysis in Turkish precipitation data," Hydrological Processes, vol. 20, no. 9, pp. 2011-2026, 2006.

[45] R. Sneyers, "Climate chaotic instability: statistical determination and theoretical background," Environmetrics, vol. 8, no. 5, pp. 517-532, 1997.

[46] R. Sneyers, H. Tuomenvirta, and R. Heino, "Observations Inhomogeneities and Detection of Climate Change The case of the Oulu (Finland) air temperature series," Transportation Research Record Journal of the Transportation Research Board, vol. 34, no. 3, pp. 159-178, 1998.

[47] H. Tabari, B. S. Somee, and M. R. Zadeh, "Testing for long-term trends in climatic variables in Iran," Atmospheric Research, vol. 100, no. 1, pp. 132-140, 2011.

[48] A. Marchetto, rkt: Mann-Kendall Test, Seasonal and Regional Kendall Tests, 2014, https://CRAN.R-project.org/package=rkt.

[49] T. Gouhier, biwavelet: Conduct Univariate and Bivariate Wavelet Analyses, 2014, http://github.com/tgouhier/biwavelet.

[50] Q. Ji, Y. Song, and H. Liu, "Characteristics of temperature and precipitation in Northeast China from 1951 to 2000," Journal of Meteorology \& Environment, vol. 22, no. 5, pp. 1-5, 2006.

[51] S. Yue and M. Hashino, "Long term trends of annual and monthly precipitation in Japan," Journal of the American Water Resources Association, vol. 39, no. 3, pp. 587-596, 2003.

[52] N. Palizdan, Y. Falamarzi, Y. F. Huang, T. S. Lee, and A. H. Ghazali, "Regional precipitation trend analysis at the Langat River Basin, Selangor, Malaysia," Theoretical and Applied Climatology, vol. 117, no. 3-4, pp. 589-606, 2014.

[53] T. Han, H. Chen, and H. Wang, "Recent changes in summer precipitation in Northeast China and the background circulation," International Journal of Climatology, vol. 35, no. 14, pp. 42104219, 2015.

[54] J. Sun and H. Wang, "Changes of the connection between the summer North Atlantic Oscillation and the East Asian summer rainfall," Journal of Geophysical Research Atmospheres, vol. 117, no. 8, Article ID D08110, 2012. 

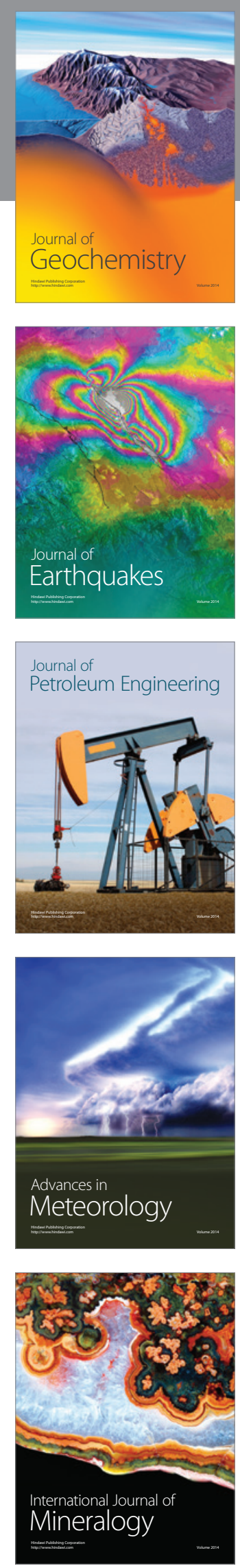
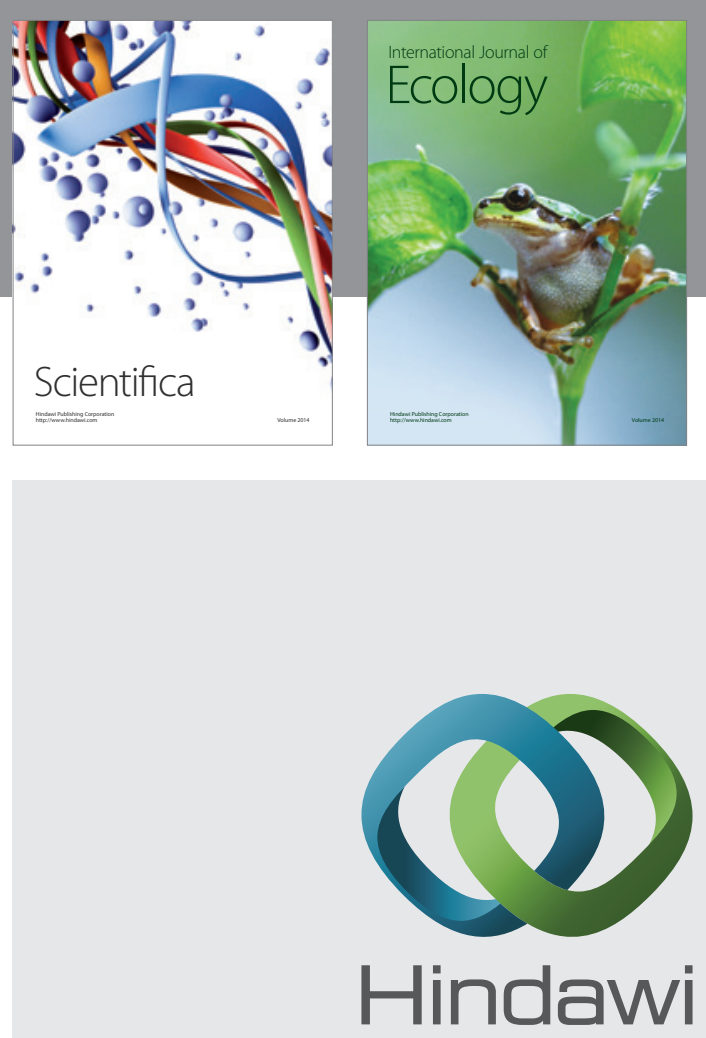

Submit your manuscripts at

http://www.hindawi.com
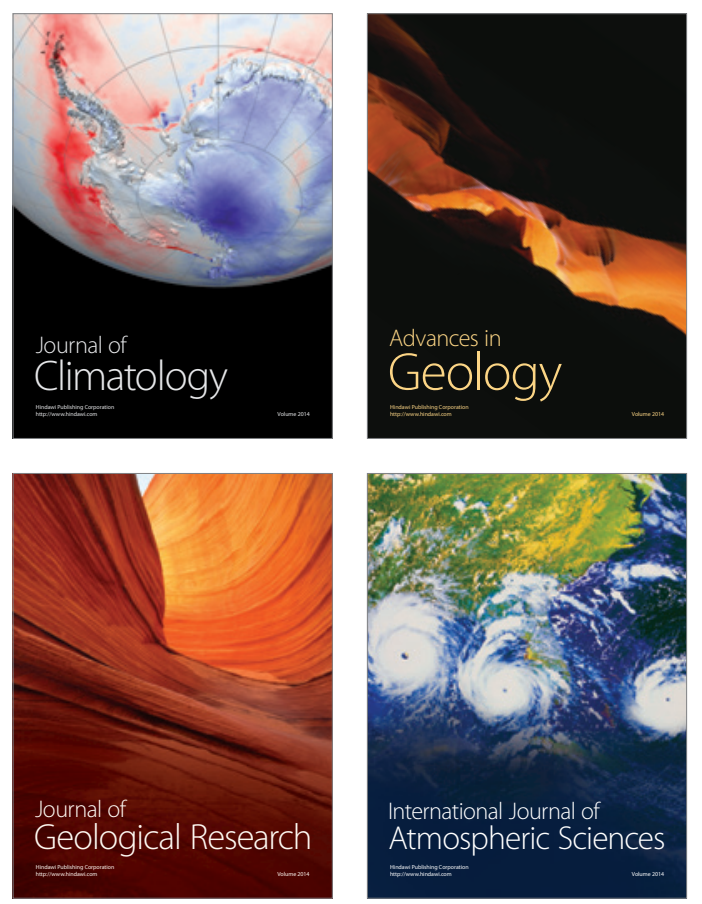

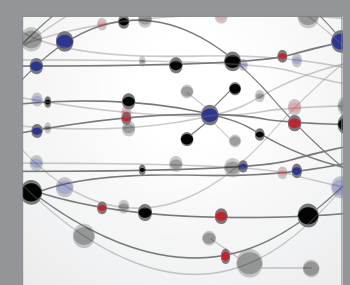

The Scientific

\section{World Journal}
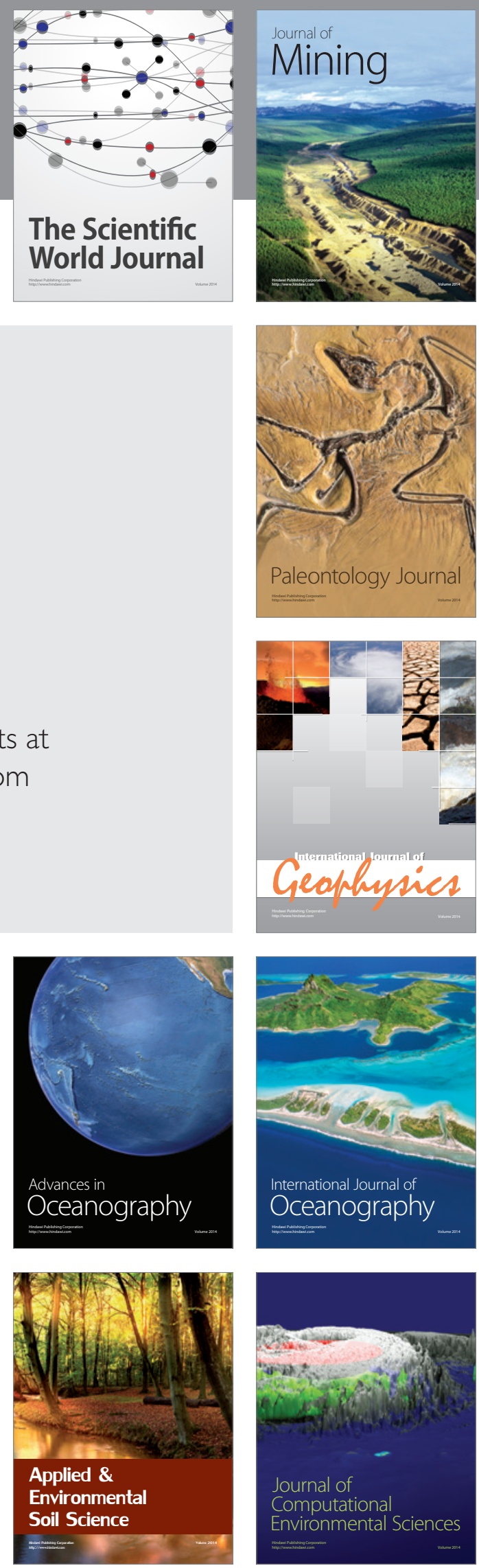